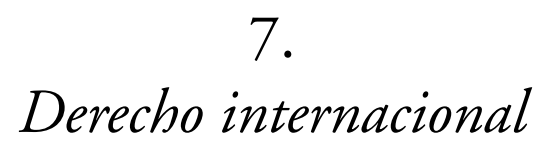



Revista de Derecho

de la Pontificia Universidad Católica de Valparaíso XXXIII (Valparaíso, Chile, ${ }^{\text {do }}$ Semestre de 2009)

[pp. 455 - 496]

\title{
LA ESTRUCTURA DEL SISTEMA JURÍDICO BOLIVIANO Y LAS RELACIONES ENTRE LAS FUENTES DE SU DERECHO SEGÚN LA “CONSTITUCIÓN" VIGENTE
}

["The Structure of the Bolivian Legal System and the Relationships Between the Sources of Their Law According to the Valid "Constitution"”]

\author{
Horacio Andaluz* \\ Universidad Privada de Santa Cruz de la Sierra, Bolivia
}

\begin{abstract}
RESUMEN
La recientemente en vigor Constitución boliviana de 2009 trae consigo cambios en la estructura del sistema jurídico. Este artículo analiza dichos cambios a través de las relaciones formales entre las distintas fuentes del Derecho y expone la estructura unitaria y a la vez territorialmente descentralizada inaugurada por la Constitución. Además de un marco teórico previo, el artículo está dividido en dos partes principales: la primera se ocupa de la Constitución como fuente del Derecho, e incluye las consecuencias jurídicas de su supremacía, los límites de la cláusula de interpretación de la Constitución y el carácter vinculante de los precedentes del Tribunal Constitucional; la segunda parte presenta las fuentes de Derecho ordinario, sus respectivas posiciones en la estructura del sistema y las relaciones formales entre ellas.
\end{abstract}

\begin{abstract}
The recently in force Bolivian Constitution of 2009 brings a change in the structure of the legal system. This paper analyzes such change through the formal relations among the legal sources and exposes the structure of the Unitarian and territorially decentralized State shaped by the Constitution. Besides a previous theoretical frame, the paper is divided into two main parts: the first one regards the Constitution as a legal source, and includes the legal consequences of its supremacy, the limits of the interpretation clause of the Constitution and the application of the stare decisis doctrine to the Constitutional Court precedents; the second part exposes the ordinary legal sources, its respective position in the structure of the legal system and the formal relations among them.
\end{abstract}

* Profesor de Derecho de la Universidad Privada de Santa Cruz de la Sierra (Bolivia). Domicilio postal: Casilla Postal 4710, Santa Cruz de la Sierra, Bolivia. Correo electrónico: handaluz@post.harvard.edu 
Palabras clave: Constitución boliviana de 2009 - Supremacía constitucional - Continuidad del sistema jurídico - Fuentes del Derecho - Estructura del sistema jurídico.
KeYwords: Bolivian Constitution of 2009 - Constitutional Supremacy - Continuity of the Legal System Sources of Law - Structure of the Legal System.

\section{INTRODUCCIÓN}

La estructura de un sistema jurídico se determina por las relaciones entre sus fuentes. Esto supone que el Derecho regula su propia creación. Pero también que el significado material de sus normas depende de las formas normativas que las albergan. Así, la determinación del significado jurídico de una norma depende de su posición en la estructura del sistema y de sus relaciones con las demás formas normativas del mismo. De manera que en el pensamiento jurídico el conocimiento formal del sistema antecede a su conocimiento material, pues lo segundo viene determinado por lo primero. De ahí la relevancia de las fuentes en la teoría general del Derecho. Ahora bien, que el estudio de un sistema positivo deba hacerse desde su norma fundacional, obedece a que la norma fundacional determina las condiciones de validez del sistema, y en esa medida determina también las relaciones entre sus formas normativas. Estas relaciones son las que configuran la estructura específica de cada sistema positivo. Que el estudio positivo de las fuentes deba hacerse desde el Derecho constitucional, responde al hecho de que son las constituciones las que, al establecer las condiciones de validez para la pluralidad de normas que articulan, dan configuración estructural a los sistemas positivos que fundan.

En este orden de ideas, lo que aquí se presenta es un análisis de las fuentes del Derecho y de sus relaciones en el marco normativo de la Constitución vigente. El análisis ha sido efectuado desde una teoría formal de las fuentes, porque sólo un enfoque bajo el criterio formal permite identificar la estructura positiva de un sistema jurídico ${ }^{1}$. Además, es sólo

${ }^{1}$ Las teorías tradicionales definen las fuentes atendiendo o bien al criterio sustantivo o bien al de la eficacia erga omnes. Por el primero, son fuentes las normas generales y abstractas; por el segundo, lo son aquellas cuya oponibilidad es absoluta. Ambos criterios tienen carácter meramente teórico, útiles únicamente a efectos de una exposición de las distintas formas normativas, pero carecen de relevancia jurídico-positiva, lo cual no puede ser de otra manera pues la diferenciación entre "actos fuente" y "actos no fuente" no comporta consecuencias jurídicas, ya que el sistema jurídico no atribuye especificidades propias a las normas por el hecho de su clasificación como fuentes del Derecho. Frente a las teorías tradicionales está la teoría formal, 
bajo el criterio formal que se puede incorporar en la categoría de fuentes tanto a la costumbre como a los precedentes judiciales. La inclusión de la costumbre es necesaria para la comprensión estructural del sistema jurídico boliviano. Respecto a los precedentes judiciales, su carácter normativo deriva de la unidad del sistema jurídico. Esto los hace exigibles en cualquier sistema positivo.

\section{CUESTIONES CONCEPTUALES PREVIAS}

\section{La estructura del sistema jurídico: la teoría formal de las fuentes del Derecho.}

La estructura formal de los sistemas jurídicos se configura a partir de las relaciones entre sus fuentes del Derecho. Las "fuentes" revelan que el sistema jurídico regula su propia creación. Esto se da al someter la producción de normas jurídicas al cumplimiento de determinadas condiciones. De este hecho es que el normativismo deriva la unidad del sistema jurídico. Tal unidad resulta de la existencia de normas que determinan los elementos que componen el sistema. Por servir como método para la identificación de otras normas, las fuentes son denominadas "meta normas", "normas sobre la producción jurídica" o, en términos de Hart², "reglas secundarias".

Estas normas regulan la introducción de nuevo Derecho al sistema jurídico. El proceso ocurre a través de: i) normas de competencia formal, que atribuyen a un órgano la competencia para producir Derecho (verbigracia el artículo 158.I.3 de la Constitución, que atribuye a la Asamblea Legislativa Plurinacional la competencia para dictar leyes); ii) normas de procedimiento, que disciplinan el curso procesal para el ejercicio de la competencia formal (para las leyes, el procedimiento legislativo de los artículos 162 a 164 de la Constitución en cuanto a la producción de leyes); iii) normas de competencia material, que determinan la materia en que puede ejercerse la competencia normativa (verbigracia el artículo 411.II de la Constitución, que atribuye competencia al órgano legislativo para reformar parcialmente la Constitución); y iv) normas de contenido, siempre que sean superiores a las normas producidas por la fuente objeto de análisis

para la cual todas las normas son fuentes, y donde el término fuente se toma como mera forma de referirse a las condiciones de validez que una norma impone para la creación de otra. Como se verá en el texto principal, es a partir de este régimen que se construye la estructura de los sistemas positivos.

${ }^{2} \mathrm{El}$ de Hart es el mejor intento orientado a construir una teoría del conocimiento jurídico alrededor del carácter dinámico del Derecho, a partir de su diferenciación entre reglas primarias (normas de conducta) y secundarias (normas de competencia). 
(así, las leyes están condicionadas por el contenido de la Constitución y los decretos por el contenido de la Constitución y las leyes).

Las tres primeras condiciones son criterios de validez de tipo dinámico (formal). Su infracción produce, respectivamente, vicios de competencia formal, de procedimiento y de competencia material. Estos vicios operan respecto de disposiciones jurídicas como formas continentes (cuyo contenido son las normas jurídicas). En cambio, la cuarta condición de validez es de tipo estático (material), cuya infracción produce un vicio material o sustantivo, que opera respecto de las normas jurídicas contenidas y no respecto de las formas continentes (disposiciones jurídicas). Habida cuenta que todas las normas son resultado de un proceso de interpretación de las disposiciones que las contienen, el vicio material no significa que sea inválida la disposición que contenga una norma inválida, sino la disposición que no contenga ni una sola norma (ni una sola interpretación posible) válida. Este es el principio de conservación de la norma, que consiste en preferir la construcción interpretativa que conserve la validez de una disposición, a la que concluya en su invalidez. Y que si en materia constitucional deriva de interpretar el ordenamiento conforme a la Constitución, para la teoría general del Derecho es un imperativo en razón de la unidad del ordenamiento.

Para la teoría formal de las fuentes del Derecho, son fuentes los actos autorizados por una norma jurídica del sistema para producir, innovar o derogar el Derecho vigente. Esta es la concepción iniciada por Merkl en sus Prolegómenos de una teoría de la construcción escalonada del Derecho (1931). Kelsen, cuya teoría del Derecho para entonces se encontraba atrapada en una concepción estática del fenómeno jurídico, introdujo a su teoría la concepción dinámica de su "querido alumno", en que se mantuvo desde la primera edición de su Teoría pura del Derecho (1934).

Para Merkl, el análisis estructural del fenómeno jurídico puede hacerse según el contenido de las normas o según su fuente de producción (forma).

\footnotetext{
${ }^{3}$ Uno de los primeros discípulos de Kelsen en la Universidad de Viena fue Merkl. Kelsen llegó a considerarlo "cofundador" de la teoría pura del Derecho al reconocer el "gran significado de su obra". De hecho, escribió que "el mérito de haber concebido y expuesto el orden jurídico como un sistema genético de normas de Derecho que van concretándose gradualmente desde la Constitución, pasando por la ley y el decreto y demás fases intermedias, hasta los actos jurídicos individuales de ejecución, corresponde a Adolf Merkl”, citado por MAYER, Heinz, La teoría de la construcción jurídica escalonada, en WALTER, Robert, Problemas centrales de la teoría pura del Derecho (1 $1^{\text {a }}$ edición, Bogotá, Universidad Externado de Colombia, 2001), p. 63. Sobre estos aspectos, véase también: KucsKo-STADlmaYer, Gabriele, La contribución de Adolf Merkl a la teoría pura del Derecho, en Revista de la Facultad de Derecho de México 244 (2005), pp. 243-258.
} 
A diferencia de las formas, los contenidos en el Derecho son inagotables. En cambio, sostiene, hay una "economía de la forma", ya que con vasta que fuese la multiplicidad de formas, frente a la diversidad de su contenido siempre tendrá un límite cierto. De ahí su fórmula: "la forma es finita, el contenido infinito" 4 .

En razón de la forma, i) la relación entre una fuente y otra se expresa en términos de delegación de poder: una fuente sólo tiene poder normativo en la medida en que le haya sido delegado por otra fuente y dentro de los límites de tal delegación; ii) cada delegación de poder determina las condiciones de validez de una norma; iii) puesto que la norma es creada por aplicación de otra (aquella que determina las condiciones de validez), la norma deriva de aquella que la autoriza, por lo que, al estar condicionada, le es inferior; formándose así, entre normas subordinantes y normas subordinadas, una cadena de validez que le da al sistema jurídico una estructura jerárquica: esta es una jerarquía lógica, que deriva de una concepción de la filosofía del Derecho sobre el proceso de producción jurídica, y que, en tanto tal, es la única estructura insita del sistema jurídico, pues se forma a partir de las relaciones de validez entre sus normas; iv) consecuencia de lo anterior es que todo acto jurídico es a la vez la aplicación de una norma y la creación de otra, poniéndose fin a la distinción entre creación y aplicación del Derecho; y, por último, vi) se disuelve la distinción conceptual entre "actos fuente" y "actos no fuente": ya que si todos los actos normativos también crean Derecho, y no sólo lo aplican, todos son también fuentes del Derecho.

Como filosofía del Derecho, la teoría formal de las fuentes es sólo un instrumento para el conocimiento y la explicación del Derecho positivo. Nada más. Es, por tanto, un error confundir la teoría con su representación gráfica en forma de pirámide. En consecuencia, es erróneo evaluar la solvencia científica de esta teoría compulsando tal representación esquemática con la estructura positiva de un sistema determinado 5 . Siendo cierto que

${ }^{4}$ Citado por MaYer, Heinz, cit. (n. 3), p. 65.

${ }^{5}$ Este es el nervio de la teoría de las fuentes de KeLSEN, Hans, Teoría general del Derecho y del Estado (5a reimpresión, México D.F., UNAM, 1995), pp. 155-156): "[...] cada norma jurídica es fuente del precepto cuya creación regula, al determinar el procedimiento de elaboración y el contenido de la norma que ha de ser creada. En tal sentido, toda norma jurídica superior es fuente de la inferior. [...]. La fuente del Derecho no es, por tanto, como la expresión parece sugerirlo, una entidad diversa del Derecho, dotada de una existencia independiente frente a éste; por sí misma, la fuente es en todo caso Derecho: una norma jurídica superior en relación con otra inferior o sea el método de creación de una norma inferior determinado por otra, lo cual constituye un contenido específico del Derecho". En tanto que razonamiento abstracto, el mérito de la teoría consiste en explicar en términos de Derecho positivo 
la graficación piramidal depaupera la teoría que pretende representar, también lo es que no se puede confundir una filosofía del Derecho, como instrumento de conocimiento, con el Derecho positivo, como objeto de conocimiento $^{6}$. La teoría formal de las fuentes sólo hace visibles los vínculos entre las disposiciones jurídicas; no los produce. Tampoco impone configuración positiva alguna de los sistemas jurídicos, pues la estructura de un sistema jurídico positivo sólo es deducible de sí mismo.

Esto lo comprendía el propio Merkl, que acompañó su teoría formal de las fuentes con su tesis de la fuerza jurídica de los actos normativos, distinguiendo la teoría estructural (descripción lógico-filosófica) de la estructura positiva de los sistemas jurídicos (descripción jurídico-positiva).

Así trazó la distinción: i) si la producción de todos los actos normativos está condicionada, entonces la dinámica de producción normativa está determinada por la norma jurídica que los condiciona (jerarquía lógica); ii) frente a esto, la pregunta a plantearse es si los órganos jurídico-positivos autorizados a producir determinados actos tendrán también la correspondiente autorización para su anulación; iii) su respuesta fue que ello depende del "ámbito de vigencia específico de lo jurídico": "lo jurídico vale en tanto que en el ámbito de fenómenos jurídicos condicionantes no sean llenados manifiestamente los presupuestos para la invalidez de los fenómenos jurídicos condicionados" (presunción de validez); iv) por tanto, el problema de la capacidad de modificación de normas jurídicas es remitido al Derecho positivo: cada sistema asigna una posición a las diversas fuentes dentro de la estructura del ordenamiento; esta es la fuerza jurídica, en tanto que capacidad de una fuente para incidir en el sistema, ya sea introduciendo nuevas normas o ya derogando las existentes (jerarquía positiva); y v) la fuerza jurídica específica de las diversas formas normativas, se determina por el grado de complejidad de sus respectivos procesos de creación, pues, salvo regla contraria, una forma normativa sólo puede declinar o innovarse

el proceso de producción normativa. Pero corresponde a cada intérprete la tarea de identificación de las específicas condiciones de validez de las formas normativas en su sistema positivo.

${ }^{6}$ Este punto ha sido tocado por Raz. Por su mayor plástica para graficar las relaciones intranormativas, él reemplaza la pirámide por el diagrama en forma de árbol, que también representa de mejor manera la organización jerárquica del Derecho y las relaciones directas e indirectas de validez entre las normas, que era el objetivo principal de Kelsen al usar el modelo piramidal, a la vez que evita las implicaciones indeseables de la pirámide, entre ellas "la más indeseable": "la apariencia de que hay siempre el mismo número de niveles en las pirámides de todo sistema positivo". Véase: RAz, Joseph, The Concept of a Legal System (2a edición, Nueva York, Oxford University Press, 1980), p. 99.

${ }^{7}$ Citado por MaYer, Heinz, La teoría de la construcción, cit. (n. 3), p. 169. 
siguiendo el mismo proceso de creación ${ }^{8}$. De ahí que la fuente originada en un proceso menos complejo no pueda prevalecer contra las fuentes originadas en procesos de mayor complejidad. De esta manera, la importancia de cada forma normativa es atribuida por el propio Derecho positivo, con independencia de las razones materiales de lege ferenda que justificaron su inclusión en el sistema como fuente del Derecho. Así, la mayor fuerza jurídica de la ley respecto al decreto se explica por la mayor complejidad de su proceso de creación (justificación positiva), sin necesidad de invocar su mayor legitimidad democrática (justificación política).

La distinción entre jerarquía lógica y jerarquía positiva no sugiere en absoluto que se den en compartimientos estancos, cual si, disociada la una de la otra, la primera rigiese en el solo plano de la especulación filosófica y la segunda en el Derecho vigente. Antes bien, es la teoría formal de la primera la que precisamente explica la estructura vigente en un sistema positivo, pues aunque la jerarquía lógica no impone la jerarquía positiva, la positiva sólo puede ser determinada en razón de la lógica, desde que las relaciones de validez que hacen a la jerarquía positiva son descritas por la jerarquía lógica. En efecto, los sistemas jurídicos no suelen tener disposiciones positivas expresas detallando escalonadamente sus estructuras normativas, y cualquiera que lo intente a lo sumo llegará a perfilar en términos muy generales la estructura real que se forma a partir de las relaciones positivas entre sus normas. Es el caso del artículo 410.II de la Constitución, como se verá en su momento.

Es por el cumplimiento de las condiciones impuestas para la validez de sus distintas formas normativas, que se determina la estructura positiva de un sistema. Esto permite configurarlo a partir de dos criterios de estructuración: i) según la jerarquía positiva que se compone en razón de la fuerza jurídica de las distintas formas normativas según el grado de dificultad para producirlas, y que resulta de combinar las normas formales de competencia con las de procedimiento (condiciones de validez i) y ii), de tal manera que los preceptos de forma más difícil tienen una mayor significación en el sistema que los que muestran una forma más sencilla (el axioma es entre más difícil la forma, más importante la fuerza); y iii) de acuerdo a la competencia material asignada a los distintos órganos formales de producción (condición de validez iii), circunscribiendo a la

${ }^{8}$ Esto descansa sobre una regla de tan vieja data en el conocimiento jurídico como que ya Ulpiano la había introducido al Digesto: "Nada es tan natural como que cada cosa se la disuelva del mismo modo como se la ligó" " Nibil tam naturale est, quam eo genere quidque disolveré, quo colligatum est": Digesto, libro I, título $3^{\circ}$, ley 37a), y que condice con el "Ejus est tollere cujus est condere": "Quien tiene poder para hacer una cosa lo tiene para deshacerla”. 
materia objeto de la respectiva asignación competencial la validez de sus correspondientes actos normativos. Como podrá verse, en este caso la estructura del sistema no se determina por la fuerza jurídica de sus fuentes, sino por las normas que atribuyen competencia material a los órganos productores, ya se trate de normas con la misma fuerza, o ya de que establezcan una reserva a favor de una fuente inferior. Por tanto, la regla es que se sustituye el criterio de jerarquía ahí donde el sistema ha introducido el de competencia material, pues el hecho de atribuir a una fuente la regulación de una materia conlleva la invalidez de aquellas que invadieran tal campo material, incluso si jerárquicamente superiores; sin que venga al caso considerar si el contenido de la norma de fuente incompetente es antinómico con el de la fuente competente, porque lo que vicia la validez del acto es el solo hecho de incursionar en campo material ajeno y, por tanto, normar sin competencia?.

De manera que la estructura positiva de un sistema jurídico se configura por la coexistencia de ambos criterios, incluso al mismo nivel jerárquico. Por lo tanto, si la Constitución es la norma suprema del ordenamiento, es ella la que configura la estructura del sistema jurídico y las relaciones entre sus fuentes, pues las relaciones dependen de la estructura. La estructura es resultante de la reconstrucción de las normas constitucionales sobre la producción jurídica. Al respecto, el propio artículo 410.II de la Constitución, atinente a la estructura del sistema, deberá ser objeto de reconstrucción, a objeto de eliminar antinomias entre su descripción literal y la estructura real que se configura tomando el íntegro del texto constitucional.

${ }^{9}$ Un ejemplo paradigmático es el de los reglamentos camerales. En este caso, existe una norma de competencia en los artículos 159.1 y 160.1 de la Constitución reservando a las cámaras legislativas la atribución de dictar sus propios reglamentos. De esta manera, aun cuando siendo de fuente superior, un reglamento legislativo promulgado por ley debe ceder ante uno aprobado por resolución cameral. La razón: respecto de esta materia en particular, el sistema está estructurado según la competencia material de los órganos productores, por lo que la ley sería inconstitucional por violar la reserva de competencia hecha por la Constitución. Ni siquiera importa preguntar si la ley es efectivamente antinómica a la resolución cameral, pues lo que la hace inconstitucional es la actuación ultra vires de su órgano productor. En este ejemplo, la jerarquía entre la ley y la resolución cameral no juega papel alguno, sólo importa la de la Constitución. Cuando se trata del criterio de competencia, la única jerarquía relevante es la de la norma que distribuye la competencia entre las fuentes en compulsa: ella tiene que ser superior a ambas fuentes, pues de lo contrario no puede condicionar la validez de éstas a través de la competencia material de sus respectivos órganos productores. Esto es lo que hace que el vicio de competencia se sustancie como una infracción a la norma jerárquicamente superior responsable de la distribución de materias (norma de competencia). 


\section{La continuidad del sistema juridico: la validez del Derecho preconsti-} tucional y la competencia formal de los órganos preconstituidos.

De la sola entrada en vigor de la norma que define las condiciones de validez del sistema jurídico (la Constitución), no se deduce la invalidez automática del Derecho preexistente, lo mismo que tampoco la incompetencia formal de los órganos productores preconstituidos. En teoría general del Derecho se dice que los sistemas jurídicos tienen vocación de persistencia, porque mantienen su identidad a pesar de que sus normas varíen. Así, visto como una línea sostenida de tiempo, el sistema jurídico aparece como una realidad de existencia continua, pero examinado en distintas secciones de la línea se revela como una sucesión de subsistemas jurídicos. Tal sucesión es causada por los actos de derogación y de promulgación de normas. De ahí que la derogación de la norma sucedida y la promulgación de la norma sucesora no produzcan una ruptura en la continuidad del sistema, sino una sucesión reglada por el Derecho positivo del propio sistema. De esto resulta que el sistema jurídico, por ser tal, ni por materia ni por tiempo puede darse en compartimientos estancos. De manera que respecto a la anterior Constitución, la de 2009 implica continuidad, no ruptura; donde el paso de una norma a otra se rige por la última, por ser el único texto constitucional positivo vigente ${ }^{10}$.

${ }^{10}$ Es un hecho incontrovertible que con el cambio de Constitución la continuidad del sistema jurídico boliviano no está en duda, aunque la fuente de validez de sus normas haya cambiado. Revisemos un poco la teoría en la materia. Es cierto que para Kelsen no existe continuidad entre dos constituciones cuando la nueva es hecha en una forma no prevista en la anterior. El caso paradigmático sería el de la revolución victoriosa, que impone un nuevo orden a partir de la fuerza de los hechos. En estos casos, si el Derecho prerrevolucionario continúa siendo válido, es porque el nuevo orden le confiere validez, sea expresa o tácitamente, y en eso consiste la ruptura de la continuidad: en la sustitución de la fuente de validez del sistema por procedimientos no previstos, pero no en la extinción del sistema, pues la existencia de los sistemas jurídicos es tan compleja como complejas son las formas sociales que regula, por lo que es necesario mucho más que este tipo de ruptura para extinguirlo. La existencia de los sistemas jurídicos es una cuestión de hecho, que se identifica con su efectividad para regular las relaciones sociales de una comunidad. Si bien es cierto la existencia de un sistema jurídico sin capacidad normativa es un contrasentido, también es cierto que el momento de la extinción del sistema no es determinable con exactitud. Kelsen sólo llegó a plantear una fórmula general: la existencia del sistema depende de un minimum de eficacia [cf. KelSEN, Hans, cit. (n. 5), pp. 137-140]. Hart fue más allá: la existencia de un sistema no puede verificarse en cortos períodos de tiempo, porque es lo suficientemente amplia y general como para tolerar interrupciones; véase: HART, H. L. A., The Concept of Law (2a edición, Nueva York, Oxford University Press, 1994), p. 118. Raz ha sido, por último, el que ha problematizado más sobre el tema. Él propone dos exámenes para determinar la existencia de un sistema jurídico: (1) el 
La continuidad es una sola realidad que en la práctica presenta estas dos vertientes: i) continuidad en el Derecho preconstitucional (las fuentes vigentes antes de la publicación de la Constitución actual); y ii) sucesión en las competencias de los órganos constitucionales preconstituidos (lo que incluye sus competencias formales para producir nuevas normas).

Respecto a lo primero, con la abrogación de la Constitución anterior, la fuente de validez del Derecho preconstitucional es ahora la Constitución de 2009. Consecuentemente, el Derecho que resulte contrario a la Constitución vigente adolecerá de una inconstitucionalidad sobrevenida, pues si bien era constitucional con referencia al contenido de la anterior Constitución, no lo sería con referencia al contenido de la vigente. La regla, por consiguiente, es que la validez del Derecho preconstitucional se determina según la Constitución de 2009. Esto implica: i) que el enjuiciamiento de su constitucionalidad debe hacerse conforme al contenido material del texto vigente; ii) que la declaratoria de inconstitucionalidad debe sujetarse al procedimiento previsto en el texto vigente; y iii) que hasta en tanto tal procedimiento no sea agotado, el Derecho preconstitucional continúa siendo válido (presunción de validez).

La existencia de una norma jurídica es un dato formal objetivo, no un juicio de valor sobre sus méritos o deméritos según la apreciación personal de sus destinatarios. Por ello que para toda la producción normativa rija la presunción de que las normas son válidas hasta que el órgano atribuido de competencia por el sistema jurídico no declare su invalidez. De manera que la invalidez de una norma también es un dato objetivo, pues, tanto como constitutivamente el sistema jurídico requiere de un acto formal para que una norma comience a existir como Derecho (verbigracia su publicación), también requiere de una declaratoria formal de invalidez para que una norma deje de existir como Derecho ${ }^{11}$. De manera que

examen de efectividad: que es preliminar y sirve para determinar si en una sociedad existe algún sistema jurídico operante, asumiendo que aunque todas sus normas son relevantes, no todas tienen la misma importancia para asegurar la continuidad del sistema; y (2) el examen de exclusión: determina cuál es el sistema existente en una sociedad, pues puede ocurrir que más de uno esté efectivamente rigiendo. El examen de exclusión pone de relieve el hecho que es artificial pretender hacer un corte general en la existencia del sistema, y que lo realista parece ser asumir que a la vez que un sistema va volviéndose ineficaz, otro va ocupando su lugar en el espacio que la ineficacia del primero le deja. Una cosa es cierta, y es que Raz tiene razón al casar la identidad de los sistemas jurídicos con la identidad de las formas sociales que regulan, porque como hecho social el Derecho es un epifenómeno de la cultura. Véase: RAz, Joseph, cit. (n. 6), pp. 188-189, 203-208, 211.

${ }^{11}$ La presunción de validez no se agota en el enunciado de su pura literalidad, sino que ella es consecuencia de distinguir entre las condiciones de validez y las con- 
respecto a cualquier norma preconstitucional que se pudiera considerar objetable de inconstitucionalidad sobrevenida, jurídicamente sólo puede decirse que según la Constitución de 2009 el Derecho preconstitucional es válido mientras el Tribunal Constitucional Plurinacional no lo declare inconstitucional. Sólo este órgano puede emitir tal declaratoria, por cuanto la Constitución le ha reservado la competencia para ejercer el control de la constitucionalidad (artículos 196.I y 202). Desde que esta competencia constituye una reserva material, ningún otro órgano del Estado puede arrogársela, como no sea violando la Constitución. Por tanto, en lo tocante al Derecho preconstitucional, hay continuidad, no ruptura.

En cuanto a las competencias de los órganos constitucionales (con extensión a todo el aparato institucional del Estado), ante todo debe tenerse presente que para extinguir un órgano constitucional la Constitución no necesita declararlo expresamente, pues basta su silencio al respecto para entender que no forma más parte de la estructura del Estado (extinción del órgano por derogación de su norma de regulación). Dicho esto, cuando la Constitución regula las competencias de los órganos constitucionales ya existentes, la continuidad del sistema jurídico se produce en la forma de una sucesión de competencias, imponiéndoles las que emanan de ella y derogando las que emanaban de la anterior Constitución. Por tanto, en las competencias de los órganos constitucionales tampoco hay ruptura, sino sucesión, por lo que no interrumpen sus funciones (incluyendo las de producción normativa), ya que la sucesión es consecuencia de la sola entrada en vigor de la Constitución.

Esto significa: i) que transitoriamente los órganos constitucionales

diciones jurídico-positivas de invalidez, pues si bien el sistema impone condiciones para la validez de sus normas, el sistema puede, por razones de seguridad jurídica, negar efecto invalidatorio al incumplimiento de algunas de esas condiciones. Merkl llama a esto el cálculo del error, nombre con el que justifica que los sistemas positivos sopesen (calculen) el peso de las condiciones de validez y decidan que el incumplimiento de algunas de ellas (las de menor importancia) no acarree la invalidez del acto afectado. En consecuencia, si el sistema positivo niega efectos invalidatorios al incumplimiento de una condición de validez, entonces tal incumplimiento no es causante de invalidez, pero si el sistema no dice nada al respecto, entonces las condiciones de invalidez son las mismas que las de validez, porque, ante el silencio del Derecho positivo el fenómeno de la invalidez vuelve a justificarse en la explicación lógica-filosófica de la validez de las normas. También es consecuencia de la presunción de validez que hayan actos que sean inexpugnables por no haber en el sistema un órgano con competencia para declararlos inválidos. Es el caso, por ejemplo, de las decisiones de los máximos órganos jurisdiccionales, que son definitivas no por su intrínseca corrección racional respecto de sus condiciones de validez, sino porque son irrevisables, y es esto lo que las hace incontrovertiblemente válidas. 
sucedidos del régimen anterior ejercen las competencias atribuidas por la Constitución de 2009 a sus sucesores, salvo aquellas que expresamente la Constitución ha reservado a los últimos; así, el Presidente de la República ejerce las competencias del Presidente del Estado (artículo 172), el Congreso Nacional las de la Asamblea Legislativa Plurinacional (artículo 158), excepto la potestad para legislar sobre las materias expresamente reservadas por las Disposiciones Transitorias Segunda y Quinta al órgano sucesor, a saber, la Asamblea Legislativa Plurinacional que entre en funciones después de las elecciones de 6 de diciembre de 2009, etc.; y ii) que hasta el empalme con los órganos sucesores los órganos constitucionales sucedidos continúan funcionando de acuerdo a la conformación que traen del régimen anterior, ya que de la regla de irretroactividad de la Constitución vigente (artículo 123) se deriva que debe ser respetado el período de funciones de sus actuales integrantes, excepto cuando la propia Constitución haya establecido una regla contraria, en cuyo caso debe preferirse por su especialidad; así, los magistrados del órgano judicial continúan en funciones hasta el vencimiento del plazo para el que fueron designados, con mucho que la Constitución vigente establezca períodos menores que los de la anterior, y que, desde luego, correrán para quienes sean designados conforme a ella; o en lo tocante a los órganos ejecutivo y legislativo conformados según el régimen anterior, si sus miembros no agotarán los períodos para los que fueron electos no se debe al hecho mecánico de pasar a una nueva Constitución, sino a que ésta expresamente ha reducido sus mandatos, como también expresamente los ha ampliado para los alcaldes, concejales y prefectos (Disposición Transitoria Primera).

En suma, el planteamiento no consiste en que debería preferirse la continuidad a la ruptura. Consiste en recordar que si sólo la continuidad se corresponde con el carácter dinámico de los sistemas jurídicos, entonces sólo la continuidad es constitucional. Lo contrario sería una interpretación ajena a las notas esenciales que definen al fenómeno normativo que llamamos Derecho, con todo lo de artificial que tiene entender algo al margen de su naturaleza. Por ello, para lo aplicable según lo expuesto, el Derecho preconstitucional sigue siendo fuente del Derecho, y los órganos productores preconstitucionales siguen teniendo poderes normativos.

\section{LA “CONSTITUCIÓN” COMO FUENTE DEL DERECHO}

\section{La supremacía de la "Constitución" y el bloque de constitucionalidad.}

La supremacía de la Constitución es una cuestión de hecho: ella es la norma suprema del sistema jurídico en la medida de su efectividad para dotar de validez a la pluralidad de normas que lo integran (de ahí 
que, en términos de eficacia, sin control de la constitucionalidad no haya Constitución). Sólo en este sentido la Constitución es la fuente de fuentes (norma normarum). La norma que si bien no regula directamente las condiciones de validez de todas las formas normativas del sistema, lo unifica al hacer que las normas que regulan la producción de cada forma concreta deriven, directa o indirectamente, de ella. Esta es la razón de la primacía constitucional, y de esto la cláusula de supremacía (artículo 410. II) es sólo una descripción del esquema de derivación constitucional de normas, no su fundamento. Fundar la primacía de la Constitución en su cláusula de supremacía es incurrir en un razonamiento circular: es afirmar que la Constitución es suprema porque ella dice que lo es.

A partir de la unidad del sistema jurídico que propugna la teoría formal de las fuentes, la supremacía de la Constitución significa: i) que en todo proceso de producción normativa debe aplicarse las normas constitucionales con preferencia a cualquier otra norma, en los términos reglados por el sistema (verbigracia, el incidente de inconstitucionalidad tratándose de la producción de una norma individualizada, como una sentencia, artículo 132 de la Constitución); ii) que la pluralidad de normas que forman el sistema debe interpretarse conforme a la unidad de las normas constitucionales: dado que ellas fundamentan la validez de todo el sistema jurídico, las normas que lo integran no pueden ser antinómicas entre sí, y si se produce una antinomia, el conocimiento jurídico está obligado a eliminarla, pues es un imposible lógico formular como descripción de normas dos disposiciones antinómicas; iii) que ante interpretaciones distintas debe preferirse aquella cuya disconformidad con las normas constitucionales no sea manifiesta (principio de conservación de la norma ${ }^{12}$; y iv) que la juris-

${ }^{12}$ La interpretación antinómica de una disposición no viene necesariamente aparejada con su declaratoria de invalidez (no debe confundirse la conservación de la norma con la presunción de su validez), pues esto depende de que el sistema haya conferido al intérprete el poder para emitir tal declaración, por lo que es concebible que en el ordenamiento coexistan interpretaciones antinómicas, de ahí que la exigencia de conservar nazca de la unidad del sistema, pues si el poder de interpretar estuviese siempre acompañado del poder de declarar la invalidez, el problema no sería la unidad, que no se vería afectada, sino la salud del ordenamiento, pues se podrían generar vacíos normativos indeseables. Por ello que la declaratoria de inconstitucionalidad de una norma no importe que ésta no sea conforme a la Constitución, sino que su disconformidad con ella sea manifiesta, es decir, que vaya más allá de cualquier duda a favor de su constitucionalidad. Muestra del profundo arraigo que el imperativo de conservar tiene en el Derecho es que ya en 1804, por mano de Marshall, la Corte Suprema de Estados Unidos lo llevó a sitial constitucional en "Murray v. Schooner Charming Betsy": "una ley del Congreso nunca debe ser interpretada de tal manera que resulte violatoria del Derecho internacional si es que hay alguna otra 
prudencia constitucional tiene preeminencia sobre las fuentes ordinarias, como consecuencia de que la Constitución ha reservado para el Tribunal Constitucional Plurinacional la interpretación autoritativa de las normas constitucionales (artículos 196.I y 202).

Ahora bien, son normas constitucionales no sólo las que integran el texto formal de la Constitución, sino también los tratados sobre derechos humanos y las normas de Derecho comunitario, que sumados al texto formal conforman una unidad normativa, a saber, el bloque de constitucionalidad (artículo 410.II de la Constitución). De manera que formalmente la validez del sistema jurídico boliviano, por efecto de la incorporación normativa prevista por el artículo 410.II, deriva de los tratados sobre derechos humanos y las normas de Derecho comunitario en el mismo grado que deriva del texto formal de la Constitución. Por derivar de una incorporación normativa, cuando se trata de la violación de normas incorporadas, el vicio de constitucionalidad no se sustancia por la violación a dichas normas per se, sino por la violación de la norma incorporante, responsable de darles rango constitucional ${ }^{13}$.

interpretación posible" (2 Cranch 64, 6 U.S. 64, 1804, p. 118). Luego, en "Parsons v. Bedford” (1830), el juez Story lo aplicaría expresamente a la interpretación de las leyes, dando lugar a la denominación de "avoidance canon" con que se conoce el principio en el Derecho estadounidense, y que por definición (regla de evitamiento) dice de su sentido: "ningún tribunal debe, ni siquiera involuntariamente, construir una interpretación que suponga una violación de la Constitución, a menos que los términos de la ley lo hagan inevitable" (28 U.S. 433, 1830, p. 448). En el Derecho privado, que es donde al parecer tuvo su origen la idea de conservación de los actos normativos, formulándosela como respuesta a los conflictos planteados por contratos con cláusulas ambiguas, hay antecedentes tan antiguos como el Digesto: "en casos ambiguos, lo más conveniente es aceptar que la cosa de que se trata más bien sea válida a que perezca" (Digesto, Ley 12, Tít. 5, Lib. 34: "Quoties in ambigua oratio est, commodissimum est, id accipi, quo res, de qua agitar, magis valeat quam pereat"). Por otro lado, el principio de conservación de la norma también tiene importancia para la teoría política de la división de poderes, como supuesto constitucional básico para la organización del Estado de Derecho, pues, en línea con la doctrina preconizada por Story, los tribunales deben asumir que los poderes han querido cumplir con la Constitución, no violarla, ya que no partir del principio importaría que de inicio se sospecha de la capacidad del legislativo y el ejecutivo para ejercer sus respectivas atribuciones con apego a la Constitución, siendo que aún para el administrado lo que debe suponerse es la buena fe y el sano propósito de su proceder.

${ }^{13}$ Propongo la denominación de "norma incorporante" porque sus efectos son los de incorporar a la Constitución normas que no están en su texto formal. En este sentido, el artículo 410.II produce a nivel constitucional los mismos efectos que a nivel contractual producen las cláusulas que establecen que determinados documentos son partes integrantes del contrato. La entidad jurídica de estas cláusulas es, como la del artículo 410.II, también la de una norma incorporante. 
En lo atinente a los tratados sobre derechos humanos, el artículo 410.II supone asumir en el texto de la Constitución la jurisprudencia del antiguo Tribunal Constitucional, que tomó el artículo 35 de la anterior Constitución como "permiso expreso" para la incorporación de normas al bloque de constitucionalidad, haciéndolo puerto de entrada de derechos y garantías tácitamente enunciadas pero no consignadas literalmente en su texto, y que por igual nacían de la soberanía del pueblo y la forma republicana de gobierno. Por lo demás, dicha construcción jurisprudencial también se fundaba en el texto formal de la Constitución, pues la declaración de inconstitucionalidad de una norma contraria al bloque se sustanciaba en razón de la violación de su artículo $35^{14}$.

Hasta aquí, se tiene que los tratados sobre derechos humanos son normas de jerarquía constitucional, siendo su supremacía (jerarquía positiva) el criterio que regula sus relaciones con las normas ordinarias del sistema jurídico. Pero la Constitución también regula las relaciones entre las normas contenidas en estos tratados y las normas contenidas en su texto formal. Estas relaciones son regidas por el criterio de especialidad. De ahí que, de presentarse una antinomia entre una norma del texto formal de la Constitución y una contenida en un tratado sobre derechos humanos, debe interpretarse el supuesto de hecho de la norma del texto formal como siendo lo suficientemente general como para cobijar el supuesto especial de la norma de fuente internacional, eliminándose así la antinomia ${ }^{15}$.

${ }^{14}$ Cf. STC 45/2006-RDI (2 de junio). Durante el proceso de cambio de la Constitución, presenté a la Asamblea Constituyente una propuesta de artículado sobre los aspectos formales que debiera regular la Constitución en materia de Derecho internacional. Uno de los artículos propuestos buscaba elevar a sitial constitucional jurisprudencia del antiguo Tribunal Constitucional sobre el bloque de constitucionalidad. El artículo propuesto decía: "Las normas de Derecho internacional sobre derechos humanos son por su materia normas constitucionales". Su motivación puede verse en ANDaluz, Horacio, El Derecho internacional en el sistema de fuentes: propuesta de artículos para la nueva Constitución de Bolivia, en Revista Boliviana de Derecho 6 (2008), pp. 93 ss. [reproducido en Anuario Mexicano de Derecho Internacional 8 (2008) y en Anuario de Derecho Constitucional Latinoamericano 15 (2009)].

${ }^{15}$ Es un equívoco decir que algunas normas constitucionales tienen rango "supraconstitucional" para referirse a que se aplican con preferencia a otras normas constitucionales. Tal designación confunde las relaciones estructurales del sistema jurídico con los modos específicos de relacionamiento intranormativo, por ello que no conciba más modo de relacionamiento intranormativo que el jerárquico, y por eso que la aplicación preferente la entienda en términos de jerarquía, como la propia palabra "supraconstitucional" mienta. Si la aplicación preferente se entiende en términos de jerarquía, entonces la "supraconstitucionalidad” sólo puede significar una de las dos siguientes consecuencias: i) o bien es una invocación al naturalismo, con lo cual las normas "supraconstitucionales" expresarían una teoría acerca del conocimiento mo- 
Repárese en el contenido del artículo 13.IV de la Constitución: "Los tratados y convenios internacionales ratificados por la Asamblea Legislativa Plurinacional, que reconocen los derechos humanos y que prohiben su limitación en los estados de excepción, prevalecen en el orden interno. [...]". El texto "y que prohiben su limitación en los estados de excepción" podría llevar a entender que sólo prevalecerán en el orden interno los tratados de derechos humanos que contengan tal prohibición. Pero esta no es una interpretación posible, porque resulta antinómica respecto a lo establecido por el artículo 410.II, por cuya virtud cualquier tratado sobre derechos humanos tiene jerarquía constitucional. En consecuencia, en términos de significado jurídico, de lo que dicho texto estaría predicando es de la especialidad de sus normas en relación con las demás normas constitucionales (tanto las del texto formal como las incorporadas). Como la unidad del sistema jurídico impide sostener que el artículo 13.IV esté diciendo lo que su tenor literal, en efecto, dice, debe rescatarse su sentido normativo apelando a su especialidad, pues es lo que permite demostrar que no contradice lo dispuesto por el artículo 410.II. Así, i) el artículo 410.II establece la supremacía constitucional llana de todos los tratados sobre derechos humanos; pero ii) eso no es antinómico con que durante el estado de excepción la aplicación de tales tratados se rija por la regla especial del artículo 13.IV reconstruido: prevalecen entre todas las normas constitucionales de la materia (supremacía constitucional llana), aquellas que prohíban la limitación de los derechos humanos durante el estado de excepción (aplicación del criterio de especialidad entre normas del mismo rango).

Que el criterio de especialidad regula las relaciones entre las normas

ral, pero no serían Derecho; ii) o bien conlleva la ordinarización de la Constitución, pues si hay normas superiores a ella, entonces no es la norma suprema, y la verdadera norma suprema, o sea la verdadera Constitución, estaría conformada por las llamadas normas "supraconstitucionales", y en esa medida sólo ellas condicionarían la validez de todo el ordenamiento jurídico, comenzando con las normas de lo que entonces habría que denominar la "Constitución ordinaria". Ahora bien, si con el término "supraconstitucionalidad" no se quiere hacer referencia a una superior jerarquía, sino al hecho de que ciertas disposiciones tienen mayor relevancia ontológica que otras, como ocurre con las disposiciones que llamamos "principios", haciendo que las primeras influyan en la determinación del significado jurídico de las segundas, entonces la "supraconstitucionalidad" sería una nueva denominación para un concepto ya conocido, a saber, el ámbito de aplicación material propio de cada disposición. En el caso de los principios, su mayor ámbito de acción es consecuencia de que los mismos reciben tal denominación porque de ellos puede deducirse otros contenidos, sea por su mayor relevancia teleológica o lo sea por su importancia axiológica. En cualquier caso, no es que se trate de normas superiores, sino de contenidos de mayor relevancia ontológica, que, por ello mismo, participan en la determinación del significado jurídico de otras normas. 
constitucionales sobre derechos humanos, está claro en el texto expreso del artículo 256.I: los tratados sobre derechos humanos que "declaren derechos más favorables a los contenidos en la Constitución, se aplicarán de manera preferente sobre ésta". Al igual que en el caso del artículo 13.IV, aquí la preferencia no está en función de la jerarquía, porque todas las normas son del mismo rango, sino de la especialidad.

Con forma de regla de interpretación, el artículo 256.II introduce al sistema una norma sobre producción jurídica. Así, establece que los derechos reconocidos en la Constitución se interpretarán de acuerdo a los tratados internacionales sobre derechos humanos "cuando éstos prevean normas más favorables". Excepto la parte entrecomillada, el mismo texto está en el artículo 13.IV. Otra vez, para ambos artículos debe entenderse que la regla de interpretación supone la especialidad de los tratados de derechos humanos respecto del texto formal de la Constitución, tomando como criterio específico de especialidad su carácter más favorable para los derechos humanos. Que la mención expresa al carácter más favorable no esté en el texto del artículo 13.IV no quiere decir que no sea parte de su significado jurídico: la razón de ser de las constituciones es instituir gobiernos de poderes limitados, por lo que la regla general para su interpretación es que debe leérsela a favor de los particulares.

No se olvide que también son normas constitucionales las de Derecho comunitario (sistemas normativos producidos por las comunidades de integración entre Estados). Por su fuente de producción, estos sistemas están compuestos por normas de Derecho originario y de Derecho derivado. Las primeras son normas de Derecho internacional convencional producidas por los Estados miembros de la comunidad, y equivalen a la Constitución de la comunidad. Las segundas son producidas por los órganos de gobierno de las comunidades. Son normas cuya validez deriva de los tratados constitutivos, pues los poderes normativos resultan de las competencias que, a través de los tratados constitutivos, los Estados miembros han atribuido a los órganos comunitarios.

A propósito del Derecho comunitario derivado, según el artículo 410. II (norma incorporante), el requisito para que una norma integre el bloque de constitucionalidad es que haya sido ratificada por el país. En el lenguaje de la Constitución, la ratificación significa: i) el acto de Derecho interno mediante el cual el órgano legislativo autoriza al ejecutivo a celebrar tratados (artículo 158.I.14); ii) el acto de Derecho internacional que expresa la manifestación del consentimiento del Estado en obligarse convencionalmente ante sus pares (artículo 255.I) ${ }^{16}$; y iii) la incorporación de los tratados al

${ }^{16}$ En cuanto a esta acepción, la mención a la ratificación en el texto de la Consti- 
Derecho interno, para que sean aplicables en este orden (artículo 257.I). Pues bien, la norma incorporante procede bajo la comprensión de este triple alcance del término, y ello es exigible, en efecto, para los tratados sobre derechos humanos y las normas de Derecho comunitario originario, porque en ambos casos se trata de normas de Derecho internacional convencional, regidas, por ende, por la Constitución tanto en su proceso de formación (participación de los órganos constitucionales) como en las condiciones para su aplicación en el Derecho interno. Empero, tratándose de normas de Derecho comunitario derivado debe tenerse en cuenta que su formación y eficacia en el Derecho interno dependerá de lo pactado en los tratados constitutivos pertinentes, que bien pueden disponer que tengan eficacia directa o que primero deban ser incorporadas formalmente al orden interno, ya sea por la vía usual de la ratificación legislativa o por mecanismos más expeditivos ${ }^{17}$. Por tanto, exigir para las normas de Derecho comunitario derivado el cumplimiento de requisitos distintos a los convenidos en los tratados de Derecho comunitario originario, supondría: i) comprometer la fe internacional del Estado en la medida de la violación que hubiese al tratado (pacta sunt servanda); y ii) violentar la propia Constitución, porque como el Derecho comunitario originario forma parte del bloque de constitucionalidad, incumplir sus normas implica violentar la norma incorporante (artículo 410.II).

Para tomar el caso de la Comunidad Andina de Naciones, los artículos 17 y 21 del Acuerdo Subregional Andino ("Acuerdo de Cartagena") atribuyen al Consejo Andino de Ministros de Relaciones Exteriores y a

tución debe entenderse referida al género de actos aceptados en el Derecho internacional para manifestar tal consentimiento. Así, la ratificación se equipara a la firma, al canje de instrumentos constitutivos del tratado, a la aceptación, a la aprobación, a la adhesión o a cualquier otra forma convenida en un tratado como medio para obligarse por él, pues todas ellas son las formas usadas en el Derecho internacional. De esta manera, integran el bloque de constitucionalidad todas las normas respecto de las cuales el Estado boliviano haya manifestado su consentimiento en obligarse, aun cuando no sea bajo la forma específica de la ratificación.

${ }^{17}$ La aplicación del Derecho comunitario derivado en el Derecho interno depende de cada acuerdo de integración. Por ejemplo, el artículo 189 del Tratado de la Comunidad Europea establece que los reglamentos son directamente aplicables en los Estados miembros, mientras que las directivas no lo son (éstas obligan a los Estados miembros en cuanto al resultado que debe conseguirse, dejándoles en libertad para elegir la forma y los medios de alcanzarlos). En el caso del "Protocolo de Ouro Preto" (Mercado Común del Sur), las decisiones, resoluciones y directivas deben ser incorporadas en los ordenamientos jurídicos nacionales mediante los procedimientos previstos en la legislación de cada país (artículo 42). Por tratarse de un proceso de integración, cada uno de los Estados miembros ha regulado procedimientos menos formales que la ratificación legislativa. 
la Comisión de la Comunidad Andina competencia para emitir Derecho comunitario derivado en la forma de Decisiones, las mismas que forman parte del ordenamiento jurídico andino (artículos 17 y 25). Como miembro de la Comunidad, Bolivia es parte del Tratado de Creación del Tribunal de Justicia de la Comunidad Andina y de su "Protocolo Modificatorio"18 (Derecho comunitario originario), del que interesan: i) el artículo 1.c, que reitera que las decisiones del Consejo Andino y de la Comisión forman parte del ordenamiento jurídico de la Comunidad; ii) el artículo 2, que dispone que las decisiones obligan a los Estados miembros desde la fecha de su aprobación por el órgano que las emitió; y iii) el artículo 3, que reconoce a las decisiones eficacia directa en los países miembros a partir de su publicación en la Gaceta Oficial del Acuerdo, excepto cuando su propio texto disponga que para ser aplicable es necesaria su incorporación en el Derecho interno mediante acto expreso. Por tanto, siempre que no se trate de esta excepción, las decisiones de la Comunidad Andina integran el bloque de constitucionalidad sin necesidad de ratificación.

Finalmente, no debe olvidarse que integran el bloque de normas constitucionales los tratados sobre derechos humanos y normas de Derecho comunitario ratificados por el Congreso Nacional durante la vigencia de la anterior Constitución, por razón de la continuidad del sistema jurídico.

\section{La lectura jurídica de la "constitución": la reconstrucción de la cláusula} de interpretación ${ }^{19}$.

También son meta normas (fuentes) las reglas de interpretación positivadas. Lo son porque al reglar la reconstrucción interpretativa de las disposiciones normativas están sujetando sus condiciones de validez al método de interpretación positivado por la regla. Esto es lo que ocurre con la "cláusula de interpretación", nombre con el que se hace referencia al artículo 196.II de la Constitución, mientras que por su "reconstrucción" se entiende la expresión de su significado jurídico una vez interpretada. En tanto interpretación de una cláusula de interpretación, el ejercicio consiste en tomar la cláusula como disposición continente y pasar de la expresión literal de su texto a las normas jurídicas que realmente contiene. Por toda justificación del ejercicio, baste advertir que por la interpretación de su cláusula de interpretación pasará a su turno todo el contenido de la Cons-

${ }^{18}$ Ratificado por Ley $N^{\circ} 1872$ de 15 de junio de 1998. El instrumento de ratificación se depositó el 18 de septiembre de 1998. El "Protocolo Modificatorio" entró en vigor en agosto de 1999 .

${ }^{19}$ Este punto es parte de un trabajo mayor, publicado en España como La justicia constitucional en el Estado de Derecho, en Revista General de Derecho Público Comparado 4 (2009). 
titución, incluyendo sus normas sobre la producción jurídica. De manera que en gran medida esta cláusula es "la constitución de la constitución". Dice la cláusula de interpretación: "En su función interpretativa, el Tribunal Constitucional Plurinacional aplicará como criterio de interpretación, con preferencia, la voluntad del constituyente, de acuerdo con sus documentos, actas y resoluciones, asi como el tenor literal del texto".

La expresión "con preferencia" es la que da a la cláusula su significado jurídico, más allá del mandato literal al intérprete de preferir la "voluntad del constituyente" ${ }^{20}$ y el "tenor literal del texto" 21.

${ }^{20}$ La frase hace referencia a la interpretación histórica. Ésta propugna: i) que el significado de las disposiciones legales debe justificarse en la voluntad del legislador; ii) que la voluntad del legislador es un buen justificativo porque la misma fue expresión de las fuentes materiales que desembocaron en la promulgación de la norma; iii) que un buen referente de las fuentes materiales, como acervo condicionante de la intención legislativa, debiera encontrarse en los trabajos preparatorios y precedentes inmediatos de los cuerpos legales, pues ellos pueden ser útiles para investigar las razones sociales y políticas en que estuvo inmersa la actividad legislativa (de ahí que la cláusula de interpretación remita a encontrar la "voluntad del constituyente" en "sus documentos, actas y resoluciones"); y iv) que, por ello mismo, el método no ata a lo que el legislador quiso decir, sino a las razones que lo llevaron a decir lo que dijo, como fuente de justificación del significado jurídico de una proposición (esto último ya es un alejamiento del planteamiento decimonónico original que trabajaba con una visión subjetiva respecto del contenido de las proposiciones jurídicas, obligando al intérprete a atar el significado de las normas a la voluntad de la autoridad normativa que las dictó, mientras que hoy se acepta que las normas son autónomas e independientes de la voluntad de su creador y, por consiguiente, del sentido que éste quiso atribuirles).

${ }^{21} \mathrm{La}$ frase se refiere a la interpretación gramatical, sobre la que cabe puntualizar lo siguiente: i) que por ella se entiende la tarea de precisar el significado de una disposición normativa haciendo un análisis lingüístico de las palabras, de los enunciados formados por ellas, del texto formado por los enunciados y del contexto extralingüístico en que discurre la disposición; ii) se entiende que cualquier análisis lingüístico se hace con referencia a las particulares acepciones usadas en cualquier campo del saber, de modo que tratándose de proposiciones de Derecho el análisis lingüístico deberá considerar el sentido especializado que algunas palabras tienen en el marco del sistema jurídico, y cuando las palabras empleadas carezcan de un significado propio en el Derecho, habrá de tomarse su sentido ordinario; iii) no supone que siempre deba acudirse a la interpretación, sino sólo cuando el texto no tiene un lenguaje claro, y donde por tal debe entenderse el que posee un significado convencionalmente aceptado; así, la antigua sentencia in claris non fit interpretatio se sigue aplicando pero con un sentido renovado; iv) la sentencia que se acaba de citar tiene el sentido de una salvaguarda para evitar la interpretación contra-literal, es decir, aquella que es contraria al significado claro de una proposición; y (v) llevada a la adjudicación constitucional, la prohibición de interpretación contra-literal puede más que el principio de conservación de la norma ("al juez no le está permitido mediante la interpretación 
En efecto, la expresión "con preferencia" envuelve: i) que los criterios proporcionados por la cláusula deben tener para el intérprete preeminencia sobre otros métodos de interpretación (sentido obvio de la cláusula); ii) que entre la interpretación según "la voluntad del constituyente" y la interpretación según "el tenor literal del texto" no existe prelación, siendo que en la práctica lo segundo puede no expresar lo primero, y aún presentar divergencias; iii) que la preeminencia asignada por la cláusula a ambos criterios no es razón excluyente de otros resultados interpretativos, a los que pueda arribarse mediante la aplicación de métodos distintos, pues el enunciado "con preferencia" tiene de suyo un claro sentido normativo, y tanto como le permite al intérprete servirse de otros métodos no puede prohibirle luego valerse sus resultados, con lo que el asunto pasa por saber bajo qué argumentos se pueden excluir los resultados contradictorios; $\mathrm{y}$ iv) que así como no significa una razón excluyente, "con preferencia" tampoco significa valor confirmatorio, en el sentido que el uso de los resultados interpretativos obtenidos por métodos no mencionados estaría condicionado a su carácter confirmatorio de los resultados obtenidos acudiendo a "la voluntad del constituyente" o al "tenor literal del texto", pues tal sería una interpretación contra-literal, es decir, una interpretación que no respeta el significado claro de una proposición, y donde por significado claro se entiende aquel convencionalmente aceptado, en que "preferir" y "confirmar" no son sinónimos.

Así, es cierto que la cláusula remite al intérprete a los métodos de interpretación mencionados, pero lo que en Derecho debe entenderse es que tal mandato no es imperativo en el sentido de obligarlo a usar uno o ambos criterios, sino de obligarlo a justificar la decisión de no aplicar ninguno de ellos, cuando existan razones excluyentes para no hacerlo. Es decir, razones cuyas peculiaridades materiales o formales las hagan imperar sobre otras razones y sean determinantes en la decisión de no aplicar los métodos mencionados en la cláusula de interpretación ${ }^{22}$.

En este sentido, los límites naturales de los métodos impuestos en la cláusula de interpretación actúan como razones excluyentes materiales de la obligación del Tribunal Constitucional Plurinacional de emplearlos. De esta manera, no puede acudirse a la "voluntad del constituyente" cuando sus

conforme con la Constitución darle un significado diferente a una ley cuyo tenor y sentido resulta evidente": SCHWABE, Jurgen, Cincuenta años de jurisprudencia del Tribunal Constitucional Federal alemán (1ª edición, Montevideo, Fundación Konrad Adenauer, 2003), p. 3.

${ }^{22}$ El concepto de "razones excluyentes para la acción” es de Raz, Joseph, Practical Reason and Norms (reimpresión, Nueva York, Oxford University Press, 2002), pp. 35 ss. 
"documentos, actas y resoluciones" simplemente no se pronuncian sobre la disposición en análisis o, pronunciándose, su interpretación no conduzca a ningún resultado o conduzca a varios resultados posibles; como tampoco puede acudirse al "tenor literal del texto" cuando el texto lleve al mismo tipo de resultados (o ninguno o varios posibles). De lo dicho deriva que cada método está limitado por las propias razones que lo justifican como tal, y de ahí que no haya método que no pueda sucumbir por agotamiento interno. De hecho, ningún método de interpretación está libre de no conducir a ningún resultado, como no está libre de conducir a varios resultados posibles. Para lo primero, recurrir a un método distinto será materia obligada. Para lo segundo, el concurso de interpretaciones posibles sólo podrá ser resuelto con un método distinto al que lo originó. Lo cierto es que cuando un método sucumbe por agotamiento interno, son las propias limitaciones del método las que devuelven al intérprete la plenitud de su libertad hermenéutica. Y es por ello que tal agotamiento constituye una razón excluyente material, ya que en este caso es la propia materia o contenido del método lo que excluye la posibilidad de aplicarlo.

Ahora bien, el agotamiento de los métodos de interpretación no es un tema controversial para la teoría del Derecho, ya que al asumir con naturalidad que una norma puede tener varias interpretaciones posibles, también asume que no hay un único método racional para justificar el significado de una proposición jurídica. Siendo así, el abordamiento del tema consiste en establecer si la propia ordenación del sistema jurídico brinda argumentos que operen como razones excluyentes formales ante el concurso de interpretaciones posibles; es decir, si la teoría general del Derecho proporciona argumentos para que el intérprete inaplique la " $v o-$ luntad del constituyente" o el "tenor literal del texto", con vista a los aspectos formales del sistema jurídico.

La respuesta pasa, primero, por el tema de la unidad del sistema jurídico. En efecto, para la teoría general del Derecho el sistema jurídico forma una unidad en la medida que la validez de la pluralidad de sus normas puede ser reconducida hacia una única norma mayor como fuente universal de validez. Ahora bien, para que un sistema jurídico forme una unidad, la norma que le provee validez debe también formar una unidad: lo que se traduce en que el seno de la Constitución no puede albergar antinomias (en la interpretación constitucional esto se conoce como principio de concordancia práctica). Hasta aquí se tiene que, con cláusula de interpretación o sin ella, una interpretación constitucional posible es aquella que se justifica en la unidad de la Constitución o, en términos negativos, que debe rechazarse aquella que quiebre la unidad del sistema, aun cuando fundada en la "voluntad del constituyente" o el "tenor literal del texto". Segundo, como 
ya se ha visto, al fundar un sistema jurídico, la Constitución establece su estructura formal, de la que son consecuencia las relaciones entre sus fuentes del Derecho y las relaciones de competencia entre los órganos constitucionales. De esta manera, también será interpretación posible cualquiera que se justifique en la estructura constitucional del sistema de competencias, debiendo inaplicarse la "voluntad del constituyente" o el "tenor literal del texto" cuando los resultados que presenten sean contrarios a la distribución constitucional de competencias (lo que en la interpretación constitucional se conoce como principio de corrección funcional).

Así, pues, tomados: i) el agotamiento interno de los métodos de interpretación; ii) la unidad del sistema jurídico; y iii) el sistema constitucional de competencias, como razones excluyentes que justifican la decisión de no aplicar la "voluntad del constituyente" ni el "tenor literal del texto", la cláusula de interpretación reconstruida dice: "El Tribunal Constitucional Plurinacional fundará sus decisiones en la voluntad del constituyente, según sus documentos, actas y resoluciones, o en el tenor literal del texto de la Constitución, salvo que no produzcan ningún resultado o que los resultados producidos sean contradictorios entre sí o con otras normas de la Constitución, o alteren el sistema de competencias por ella establecido, en cuyo caso las fundará en otros criterios". Y esta es la norma que debe aplicarse a la interpretación de las normas constitucionales.

3. El carácter normativo de los precedentes judiciales: sus efectos vinculantes $^{23}$.

La unidad del sistema jurídico exige que los precedentes constitucionales gocen de preeminencia sobre el Derecho ordinario, pues su órgano productor es el único autorizado por el sistema para pronunciarse autoritativamente sobre la Constitución (artículo 196).

En los sistemas jurídicos de tradición civil, el papel del juez se considera más restringido y modesto que el papel que sus pares desempeñan en los sistemas jurídicos de Derecho común ("Common law"). La razón de esta diferencia está en el efecto vinculante que los precedentes judiciales tienen en los sistemas de Derecho común, es decir, en la obligación que tienen los jueces de resolver casos similares conforme a sus propias decisiones, las decisiones de sus pares o las de sus superiores; mientras que en la tradición

\footnotetext{
${ }^{23}$ Este punto está formulado en argumentos de teoría general del Derecho, válidos para cualquier sistema jurídico positivo, por eso que se apoye en la unidad del sistema como tesis central. Para un análisis específicamente constitucional y lo suficientemente amplio sobre el efecto vinculante de los precedentes constitucionales en Bolivia, véase: Asbun, Jorge, Estudios constitucionales (1 ${ }^{a}$ edición, Santa Cruz, El País, 2008), pp. 73-116.
} 
civil el carácter normativo de los precedentes, más allá del caso en litigio, es resistido.

Esta resistencia se explica por: i) la influencia de la Revolución Francesa, que, en su afán de imponerse al antiguo régimen, llevó la división de poderes al equívoco de asumir que sólo el cuerpo legislativo creaba Derecho, asegurándose de antemano que la judicatura acompañase el proceso revolucionario juridizado por la Asamblea Nacional24; ii) la ideología de la codificación, que, como producto del naturalismo racionalista de los siglos XVII y XVIII, creyó haber encontrado unas leyes universales llamadas a regir el comportamiento humano, exagerando la importancia de los códigos como si fueran los depositarios de todo el Derecho; y iii) el predominio de la Escuela de la Exégesis, que, como consecuencia de los dos puntos anteriores, describió al juez como un puro aplicador mecánico de las leyes, pues, por un lado, no podía participar en el proceso de creación del Derecho, porque esa labor le correspondía a la legislatura, y, por otro, la interpretación e integración del Derecho, como fuentes tradicionales de su poder, ya no tenían razón de ser, dado que el alto grado de perfección supuestamente alcanzado en los códigos las hacían innecesarias.

Pues bien, lo cierto es que ninguna de estas razones es de Derecho positivo. Por el contrario, en el sistema de Derecho vigente no hay norma que niegue a los precedentes judiciales su efecto vinculante. El punto de partida de esta afirmación es la unidad del sistema jurídico, que presupone la unidad de su norma fundacional. En este sentido, siempre que la norma fundacional de un sistema, además de establecer las formas de creación de nuevo Derecho, tenga un contenido material —el que fuera—, el respeto al precedente será un elemento de dicho sistema, pues que los casos similares sean decididos de modo similar importa mantener tal unidad.

Hasta aquí la teoría del Derecho; ahora su aplicación. Resulta que: i) la Constitución no sólo es una norma dotada de contenido, sino que: ii) parte de ese contenido consiste en la igualdad de las personas ante la ley y en la garantía de seguridad jurídica ${ }^{25}$; lo que: iii) significa que ante todos

${ }^{24}$ De hecho, hasta tiempos prerrevolucionarios los jueces continentales actuaban de manera similar a sus colegas ingleses, desarrollando un cuerpo de normas de Derecho común y su propia doctrina del precedente. Esto fue interrumpido por la Revolución, que reclamaba el monopolio en la producción jurídica para poder consolidar sus reformas por medio del Derecho (cf. Merryman, John Henry, La tradición jurídica romano-canónica ( $8^{\mathrm{a}}$ reimpresión, México D. F., Fondo de Cultura Económica, 2003), pp. 47-59, 72-80).

${ }^{25} \mathrm{La}$ exigencia de seguridad jurídica es insita a todo sistema jurídico, desde que ella supone la realización de su premisa conceptual formal por excelencia, a saber, el cumplimiento de sus normas. 
los hechos "A" el Derecho debe ser "B" (se entiende que "A" supone la identidad fáctica del supuesto y sus circunstancias), por lo que, en consecuencia, iv) de la propia Constitución nace el respeto a los precedentes, en sus respectivas materias, del Tribunal Constitucional Plurinacional, del Tribunal Supremo de Justicia y del Tribunal Agroambiental, por cuanto (5) si ante los hechos "A" el Derecho no fuera "B", sino indistintamente "C", "D" o "E", entonces no habría igualdad ante la ley ni tampoco habría garantía de seguridad jurídica.

En contra del respeto al precedente se ha invocado la independencia judicial. Pero tal argumento olvida que si bien los tribunales no están sometidos a ningún otro poder, sí lo están a la Constitución, que es de donde emana el imperativo de unidad del sistema jurídico, y que conlleva el respeto al precedente ${ }^{26}$.

Y si por independencia judicial se quiere significar el Derecho de los jueces a decidir según su propio razonamiento jurídico, entonces lo que debe recordarse es que el respeto al precedente no implica hacer del precedente algo de suyo inalterable, porque lo que ello conllevaría es la pretensión de estancar la historia y estancar el raciocinio jurídico. Lo que el respeto al precedente implica es el imperativo jurídico de alterarlo sólo con base en la construcción de argumentos que justifiquen debidamente su reversión como precedente. Y donde, desde luego, se entiende que el precedente no está constituido por el texto de la sentencia ni únicamente por su parte resolutiva, sino, con un criterio de razón suficiente, por el Derecho declarado aplicable a las hipótesis necesarias para justificar la decisión. Por tanto, no hacen parte del precedente las cuestiones incidentales, como referencias doctrinales, citas de Derecho comparado, mención a disposiciones jurídicas aplicables al asunto pero no decisivas para su resolución, o los hechos que, aunque considerados, no son determinantes para justificar la decisión final; todo lo cual se conoce como dicta, que no importa jurisprudencia ${ }^{27}$.

${ }^{26}$ En su momento, la Corte Suprema de Justicia llegó a hacer uso de su iniciativa legislativa para presentar un proyecto de ley modificatoria del artículo 41.I de la Ley $\mathrm{N}^{\circ} 1836$ de 1 de abril de 1998, de tal manera que los poderes públicos sólo estuviesen vinculados por las decisiones del Tribunal Constitucional pronunciadas en las acciones de inconstitucionalidad, mas no así por la jurisprudencia formada en las acciones de tutela. Véase: Rivera SantibáÑEz, José Antonio, El Tribunal Constitucional en el nuevo modelo de Estado, en Justicia constitucional y Estado de Derecho 10 (2006), p. 157.

${ }^{27}$ Decía Goodhart, Arthur L., Determining the Ratio Decidendi of a Case, en Yale Law Journal 40 (1930), p. 182, que el precedente se encuentra "tomando los hechos considerados por el juez y su decisión en tanto que basada en ellos". El antiguo Tribunal Constitucional se refirió a la identidad de hipótesis de hecho de los 
Así entendido, lejos de contraponerse a la independencia judicial, el respeto al precedente la reafirma, pues si la precondición para que el órgano judicial sea verdaderamente inmune a las presiones, es que exista con la dignidad de un auténtico poder del Estado ante los ojos del ciudadano, es a ello que contribuye el carácter vinculante de sus decisiones. En efecto, i) la unidad de la jurisprudencia beneficia al ciudadano, por redundar en certeza y previsibilidad respecto de las decisiones de los poderes públicos, incluyendo las judiciales (de ahí que Llewellyn dijera que "aun cuando los predecesores hubiesen sido malos, ignorantes, tontos o parcializados, la certeza de que sus sucesores seguirán sus precedentes da la base para que se pueda prever las acciones de los tribunales" ${ }^{28}$ ); ii) las garantías del ciudadano penden del supuesto de que el poder frene al poder, y ya que ello supone la eficacia del Derecho como sistema de seguridad, es preferible que la interpretación autoritativa de la Constitución y las leyes sea vinculante, a que no lo sea, ya que el decisor que basa sus acciones en normas está adelantando sus futuras decisiones, lo que satisface a un principio general de consistencia, que hace a la necesidad misma de seguridad jurídica; y iii) el tema también envuelve la cuestión de la unidad del sistema jurídico, $y$, otra vez, la unidad redunda en la eficacia del sistema, al conllevar la realización de sus premisas conceptuales mismas, y donde la premisa por excelencia de cualquier sistema normativo, incluso de uno totalitario, es que la sola existencia de normas de aplicación cierta ya supone limitar la arbitrariedad.

\section{LAS FUENTES DE DERECHO ORDINARIO}

\section{Los tratados.}

Como fuentes de Derecho interno, interesan los tratados incorporados al ordenamiento a través de su ratificación (artículo 257.I). En lo que se refiere a la posición de los tratados en el sistema jurídico, el texto expreso

precedentes (es decir, el elemento "A" en la fórmula Si es "A" debe ser "B"), como "analogía fáctica”, queriendo decir con ello que las hipótesis que fundan la decisión en un caso deben ser las mismas en otro, para que a éste se aplique el precedente sentado (cf. AC 004/2005-ECA, 16 de febrero). No se debe, pues, confundir la analogía a la que hacía mención el Tribunal con la analogía como procedimiento de integración del Derecho ante la insuficiencia de legislación expresa, pues ésta importa el análisis de dos situaciones de hecho, a efectos de argumentar una semejanza suficiente como para que se justifique la aplicación, al caso no reglado, de la solución prevista expresamente por el ordenamiento para el caso reglado (cf. STC 221/2004RAC, 12 de febrero).

${ }^{28}$ Llewellyn, Karl, The Bramble Bush (reimpresión, Nueva York, Oceana/ Oxford University Press, 1961), p. 65. 
de la Constitución plantea una antinomia: por un lado dice que los tratados se aplican con preferencia a las leyes (artículo 410.II), pero, por otro lado, también dice que los tratados tienen rango de ley (artículo 257.I).

Una primera forma posible de eliminar la antinomia pasaría por interpretar que la Constitución establece tres regímenes jerárquicos para los tratados: i) rango constitucional, para los tratados que integran el bloque de normas constitucionales; ii) rango supralegal, para los tratados sobre las materias listadas en el artículo 257.II y para los de cualquier materia a los que eventualmente, por solicitud del cinco por ciento de los ciudadanos registrados en el padrón electoral, se les aplique el procedimiento del artículo 259.I: la superioridad de estos tratados se fundaría en las mayores complejidades de su procedimiento de creación, ya que para ellos se exige su aprobación por "referendo popular vinculante previo a [su] ratificación" (artículos 257.II y 259.I), por lo que, al tener una forma más difícil, es aceptable al pensamiento jurídico que se les reconozca mayor jerarquía que a los tratados que siguen la ratificación legislativa ordinaria (artículo 158.I.14); y iii) rango legal (artículo 257.I), aplicable como criterio residual a todos los demás tratados, que se relacionarían con las leyes por el criterio de temporalidad, pudiendo ser derogados por ellas, sin perjuicio de la consiguiente responsabilidad internacional del Estado en la medida que resultaran incumplidas sus obligaciones internacionale ${ }^{29}$.

El problema de esta construcción es que reduce el ámbito de aplicación material del artículo 410.II, haciendo que el rango supralegal sea aplicable sólo a los tratados para los que eventualmente se recurra al referendo popular y a los tratados sobre cuestiones limítrofes, porque, salvo éstos, todos los demás listados en el artículo 257.II versan sobre cuestiones de integración, vale decir, sobre materias de jerarquía constitucional, por tratarse de normas de Derecho comunitario (bloque de constitucionalidad). En consecuencia, se habría formulado una excepción tan amplia como la regla expuesta en el artículo 410.II.

Otra forma posible de eliminar la antinomia es reconstruir los artículos 257.I y 410.II según el criterio de fuerza jurídica pasiva (capacidad de resistencia de una norma frente a otras). En esta interpretación, los tratados (todos menos los del bloque de constitucionalidad) tendrían jerarquía

${ }^{29}$ Que una ley derogue a un tratado no significa la terminación de éste, pues su terminación, así como su formación, es una cuestión de Derecho internacional, no de Derecho interno. Esta derogación sólo supone su inaplicabilidad en el ámbito interno y, por tanto, en la medida que su inaplicación suponga incumplimiento de sus términos, acarrea la responsabilidad internacional del Estado por el incumplimiento de los mismos, causado por un acto propio, a saber, la promulgación de la ley derogante del tratado. 
formal de ley (artículo 257.I), pero, a pesar de su rango de ley, otras normas con el mismo rango no podrían derogarlos, en virtud a su aplicación preferente sobre ellas, donde habría que asumir que tal preferencia se debe a su mayor fuerza jurídica pasiva; es decir, que las otras normas del mismo rango serían incapaces de incidir en los tratados, porque al comportar su formación el concurso de voluntades de dos o más Estados, obedecen a un proceso de producción más complejo.

La ventaja de esta interpretación es que el criterio de temporalidad no se aplicaría a las relaciones entre los tratados y las demás normas con rango de ley, con beneficio del cumplimiento de las obligaciones internacionales. Además, el recurso al concepto de fuerza jurídica pasiva permite eliminar la antinomia entre los artículos en pugna sin desmedro de su ámbito de aplicación material.

2. Las leyes nacionales, los estatutos autonómicos, las cartas orgánicas y el resto de legislación departamental, municipal e indígena.

El artículo 410.II.3 de la Constitución presenta en el mismo nivel estructural del sistema jurídico a "las leyes nacionales, los estatutos autonómicos, las cartas orgánicas y el resto de legislación departamental, municipal e indigena", "de acuerdo a las competencias de las entidades territoriales" (artículo 410.II). Esta descripción es suficiente respecto a las relaciones formales entre leyes nacionales, estatutos autonómicos y cartas orgánicas, pero no respecto a las relaciones de las leyes entre sí, ni a las del resto de la legislación departamental, municipal e indígena con referencia a los estatutos autonómicos, cartas orgánicas y leyes nacionales.

Lo cierto es que las relaciones formales entre estas fuentes producen una estructura de tres niveles jerárquicos: i) por su fuerza jurídica, las leyes que deben ser aprobadas por dos tercios de votos son superiores a las leyes ordinarias y a los estatutos autonómicos y las cartas orgánicas; ii) en un nivel intermedio están las leyes para cuya aprobación basta la mayoría absoluta, los estatutos autonómicos y las cartas orgánicas, cuyas relaciones mutuas se rigen por la competencia constitucional atribuida a sus respectivos órganos productores; y iii) las demás normas departamentales, municipales e indígenas están subordinadas a sus respectivos estatutos autonómicos y cartas orgánicas, en la medida que constituyen las normas supremas de los subsistemas descentralizados y autonómicos, y, en consecuencia, las fuentes que les proveen de validez ${ }^{30}$.

${ }^{30}$ Un sistema jurídico puede estar compuesto por distintos subsistemas. Esto es lo que ocurre con los subsistemas estaduales en relación al sistema federal, con los subsistemas autónomos y descentralizados en relación al sistema nacional, o con los subsistemas nacionales con relación a los sistemas supranacionales de integra- 
En cuanto al primer nivel, el procedimiento de formación de las leyes exige que sean aprobadas por mayoría absoluta (artículo 163), excepto las que deben aprobarse por dos tercios. Integran esta excepción las leyes expresas levantando la prohibición de asentamiento de extranjeros en la zona de seguridad fronteriza ${ }^{31}$ (artículo 262.I), la Ley Marco de Autonomías y Descentralización (artículo 271.II) y la Ley de Reforma Constitucional (artículo 411.II). La última no será tratada aquí, pues no es una fuente por sí misma, sino parte de un procedimiento para la reforma parcial de otra fuente, a saber, la Constitución.

Pues bien, i) en su relación con las leyes aprobadas por mayoría absoluta (leyes ordinarias), las leyes aprobadas por dos tercios tienen mayor fuerza jurídica, la misma que deriva de la mayor complejidad que la Constitución exige para su producción, y de ahí que el criterio de temporalidad no se aplique a sus relaciones con las leyes ordinarias; ii) el efecto de la mayor fuerza jurídica alcanza sólo a las materias para las que la Constitución exige aprobación por dos tercios, de manera que inclusive dentro de la misma ley (expresa o Marco) pueden haber disposiciones que, votadas por dos tercios, no tengan mayor fuerza que las leyes ordinarias, si no constituyen materia que debe ser legislada por dos tercios; iii) el hecho que la Constitución delimite el ámbito de legislación propio de cada ley aprobada por dos tercios (artículos 262.I y 271.I), supone la unidad de materia en su tratamiento; así, la ley expresa del artículo 262.I no puede legislar materias de la Ley Marco del artículo 271.II, y viceversa, porque violarían las disposiciones constitucionales que delimitan el ámbito de legislación propio de cada forma; deriva de esto que entre ambas no se aplica el criterio de temporalidad; iv) una ley ordinaria que legislase materias sujetas al procedimiento de dos tercios sería inconstitucional, por violar las disposiciones de reserva de tal procedimiento (artículos 262.I y 271); v) la relación de la ley expresa del artículo 262.I con los estatutos autonómicos y las cartas orgánicas se define por la competencia material de sus órganos productores y la unidad de

ción o a las normas de Derecho internacional. Esta pluralidad de subsistemas forma una unidad sistémica cuando la validez de sus respectivas normas fundacionales es reconducible a una única norma, porque en términos de unidad la pluralidad de subsistemas sólo es cognoscible desde una perspectiva monista. Esto es, a partir del "requerimiento epistemológico de que todo el Derecho sea considerado en un solo sistema”, porque el conocimiento jurídico tiene la tarea de presentar su objeto de estudio (el material jurídico) como una unidad [KeLSEN, Hans, Introduction to the Problems of Legal Theory (1 ${ }^{\mathrm{a}}$ reimpresión, Nueva York, Clarendon Press, 2002), p. 111]. En términos de ciencia jurídica, así es como conceptualmente debe leerse el pluralismo jurídico al que se refiere la Constitución (artículo 1).

${ }^{31}$ Esta prohibición ingresó a la Constitución en las reformas de 1938, aunque recién ahora se exige una votación calificada para su levantamiento. 
materia en su tratamiento; así, sin importar su mayor jerarquía, por la ley expresa la Asamblea Legislativa Plurinacional no puede legislar lo que es materia de los órganos deliberativos territoriales (artículo 275); y vi) en su relación con los estatutos autonómicos y las cartas orgánicas, la Ley Marco condiciona su validez, en la medida que regula el procedimiento para su formación y operatividad (artículo 271.I), pero su capacidad normativa está limitada por la competencia material que la Constitución atribuye a las entidades territoriales descentralizadas y autónomas.

Respecto a las leyes que requieren votación calificada, habría sido útil incorporar al sistema jurídico boliviano las leyes orgánicas y estatutarias, ya que, por su propia materia (las primeras referidas a la organización de los poderes públicos y las segundas a los códigos), estas leyes debieran ser invulnerables a las modificaciones incidentales del legislador ordinario ${ }^{32}$.

Respecto a las leyes ordinarias, los estatutos autonómicos y las cartas orgánicas (nivel intermedio), la relación entre estas formas normativas se define por la competencia material atribuida por la Constitución a sus respectivos órganos productores, con lo que carece de relevancia el criterio de temporalidad. Por tanto, el acto normativo producido por fuente incompetente será inconstitucional por violar la distribución constitucional de materias entre los distintos órganos legislativos. De manera que, siendo cierto que sólo las leyes rigen para todo el territorio nacional (artículo 145), también lo es que sólo son válidas si legislan materias de competencia de la Asamblea Legislativa Plurinacional. En este sentido, la organización institucional de las entidades territoriales descentralizadas y autónomas queda excluida del ámbito de las leyes, por cuanto es la Constitución la que dispone que tal competencia normativa corresponda a los órganos deliberativos de las entidades territoriales (artículo 275). Del mismo modo, los estatutos autonómicos y las cartas orgánicas no son fuentes competentes para legislar sobre las materias listadas en el artículo 298.I de la Constitución, porque son competencias privativas del nivel central de gobierno, por tanto, materia de ley.

Respecto al "resto de la legislación departamental, municipal e indige$n a$ ”, i) tal legislación no está al mismo nivel que sus respectivos estatutos

${ }^{32}$ Las leyes que en Bolivia reciben la denominación de orgánicas, como en su momento la antigua Ley Orgánica de Municipalidades (Ley N 696 de 10 de enero de 1985) o actualmente la Ley Orgánica del Ministerio Público (Ley No 2175 de 13 de febrero de 2001), sólo dan cuenta de su objeto de regulación (un órgano público), pero no dicen nada respecto a su fuerza jurídica, pues todas ellas son por igual leyes ordinarias, con lo que lo de "orgánicas" termina siendo un puro nombre, pero no un efecto jurídico atribuido por la Constitución a una forma específica de fuente legislativa. 
autonómicos y cartas orgánicas, porque estos instrumentos son las normas supremas de los distintos subsistemas normativos descentralizados y autónomos, por lo que las normas que producen los órganos de dichos subsistemas le son inferiores, ya que de ellos derivan su validez; ii) por pertenecer a subsistemas normativos distintos (el "resto de la legislación departamental, municipal e indígena" pertenece a los subsistemas descentralizados y autónomos, y las leyes al subsistema central), entre la legislación descentralizada y autónoma y la legislación central no se producen relaciones formales de jerarquía, temporalidad ni especialidad; iii) los conflictos entre la "legislación departamental, municipal e indígena" dicen relación con las respectivas competencias que constitucionalmente han sido atribuidas a sus órganos productores, resolviéndose con la inconstitucionalidad del acto ultra vires, sea que el vicio se sustancie como un conflicto de competencias entre los órganos productores (artículo 202.3) o como un conflicto normativo por violación de la distribución constitucional de competencias (artículo 202.1); y iv) la legislación departamental, municipal e indígena de cada uno de los distintos subsistemas descentralizados y autónomos, se aplica en sus respectivos ámbitos territoriales, por lo que es un imposible lógico-normativo que entre normas de subsistemas distintos se produzcan antinomias.

\section{El Derecho consuetudinario: el Derecho indigena originario campesi-} no.

La Constitución dice del Derecho indígena originario campesino que es un "vinculo particular de las personas que son miembros de la respectiva nación o pueblo indígena originario campesino" (artículo 191.I). Este Derecho es de fuente consuetudinaria, pues lo de "vínculo particular" dice de la convicción de obligatoriedad jurídica (opinio iuris) que acompaña a determinada práctica (consuetudo), haciendo que la conducta contraria se considere ilícita entre los miembros de la comunidad que la comparte, y donde se considera nación o pueblo indígena originario campesino a "toda colectividad humana que comparta identidad cultural, idioma, tradición histórica, instituciones, territorialidad y cosmovisión, cuya existencia es anterior a la invasión colonial española" (artículo 30.I). Esta fuente de producción normativa es, por tanto, una forma jurídica propia de los subsistemas normativos indígena originario campesinos (autonomías indígenas), cuya capacidad normativa deriva de la distribución constitucional de competencias entre los distintos subsistemas (central, y autónomos y descentralizados), y de donde resulta que la regulación consuetudinaria únicamente puede tener por objeto las materias atribuidas a los subsistemas indígena originario campesinos en sus respectivos estatutos autonómicos, por cuanto aun cuando la existencia de 
estos pueblos sea "anterior a la invasión colonial española”, lo cierto es que su anterioridad histórico-cronológica (su existencia prerrepublicana) no es igual a la anterioridad lógico-normativa de la Constitución (su primacía sobre el Derecho indígena originario campesino) $)^{33}$.

En el Derecho interno la costumbre como forma de producción del Derecho decayó a la par que el Estado moderno se consolidaba. Éste se construyó a partir de la noción de soberanía, entendida como poder absoluto y perpetuo y cuyo ejercicio se traduce en la facultad de dictar leyes, contra las que no pueden primar las leyes de otros Estados ni las costumbres de sus súbditos ${ }^{34}$. De esta manera, el monopolio estatal de la

${ }^{33}$ No debe confundirse la realidad histórica con la realidad normativa. Si se trata de la distribución de competencias entre distintos subsistemas, el dato determinante son las normas que hacen tal distribución, las mismas que sólo pueden ser superiores a los subsistemas, porque de lo contrario no podría explicarse la unidad del sistema jurídico. Piénsese, por ejemplo, en el hecho que Connecticut fue la primera colonia inglesa en América en tener una Constitución ("Fundamental Orders"), que data de 1639, pero que, al formar parte de la federación estadounidense, su anterioridad histórica quedó sometida a la anterioridad normativa de la Constitución federal, promulgada más de un siglo después (1787). Lo mismo respecto de los cantones suizos, donde la existencia independiente de algunos de ellos va tan atrás como hasta 1291, cuando suscribieron una "Carta de la Alianza" para luchar contra el Sacro Imperio Romano Germánico. Pues bien, entrada en vigor la Constitución federal suiza de 1848, la anterioridad histórica de los sistemas cantonales se sometió a la anterioridad normativa de la norma que los unifica, convirtiéndose en subsistemas del sistema federal. Lo mismo ha ocurrido en el proceso de unificación de los países europeos tal como hoy los conocemos, y lo mismo es lo que ha venido ocurriendo con el progresivo proceso de centralización de la Unión Europea, que en la medida que más se centraliza, más condiciona los sistemas de sus Estados miembros, con mucho que sus miembros preexistan a la Unión. De estos ejemplos, el punto que queda es este: cuando sistemas jurídicos preexistentes (anterioridad histórico-cronológica) pasan a formar parte de un sistema mayor, su validez se subordina a las normas de éste (anterioridad lógico-normativa), lo mismo que la norma anterior se subordina a la norma posterior superior (como el Código Civil de 1975 lo hace respecto a la Constitución de 2009).

${ }^{34}$ La soberanía es un concepto histórico: "El concepto de soberanía es tan reciente como el Estado moderno. De hecho, aparece a causa de las circunstancias contra las que el Estado moderno en germinación debió enfrentarse para llegar a constituirse como tal. En sus orígenes, el Estado moderno fue atacado simultánea y constantemente por dos flancos: desde arriba por la Iglesia y el Imperio Romano, y desde abajo por los señores feudales y las corporaciones. Mientras que la Iglesia quería poner al Estado a su servicio y someterlo a su poder, el Imperio Romano pretendía no reconocerle valor superior al que había reconocido a sus provincias desde las épocas de la Lex Julia Municipalis. Por su parte, los señores feudales y las corporaciones se concebían como poderes independientes y enfrentados al Estado. De hecho, el pueblo estaba sometido primero a los barones y sólo indirectamente al rey. En el sistema feudal el 
producción jurídica es resultado del proceso histórico de consolidación del Estado moderno. De ahí que, desde sus albores, los teóricos del Estado moderno, en el entendimiento de que la unidad política no era alcanzable

pueblo prestaba fidelidad a sus señores, los barones, y cuando necesitaban acudir en justicia, acudían a los tribunales de sus señores. Los señores feudales tenían, en efecto, razones suficientes para considerarse enfrentados al Estado, puesto que sus poderes y derechos de carácter público eran los que corresponderían al Estado que terminaría por imponerse, reclamando para sí los poderes de imperium ejercidos por los señores. Es en medio de estas circunstancias que surge el concepto de soberanía. En el mundo antiguo no había nada que se opusiera al poder del Estado como los poderes que se opusieron al Estado moderno. Por ello que entonces no hubiera necesidad de un concepto como el de soberanía. En el caso de Roma, no había motivo para comparar el poder del Estado romano con un poder superior, igual o siquiera próximo al suyo. Por eso que los romanos no se vieran impelidos a elaborar el concepto de soberanía. Las expresiones maiestas, potestas e imperium, decían de la potencia y la fuerza del pueblo romano, su poder civil y militar, pero no indicaban nada del contenido y las limitaciones del Estado ni de la independencia de Roma respecto de los poderes extranjeros. El concepto de soberanía se debe a particulares circunstancias históricas. La soberanía es, pues, una categoría histórica (Jellinek). Aún durante la Edad Media la doctrina oficial dominante consideraba a todos los Estados cristianos como subordinados de Derecho al Imperio Romano. Pero esta doctrina tuvo que adaptarse. El Derecho a la independencia de los príncipes y las ciudades, como ocurrió con Florencia y Pisa, tuvo una marcada influencia privatista, propia de la época. El emperador concedía la independencia en virtud de la prescripción por posesión inmemorial. La independencia no se consideraba como propia de la naturaleza del Estado, sino como consecuencia de un título jurídico revocable. Pero la idea de soberanía no es fruto de esta doctrina oficial ni de los esfuerzos del Imperio por adecuarse a los nuevos tiempos sin perder su poder imperial. El concepto de soberanía es propiamente francés. Es Francia que le da su carácter absoluto. Pero no debe olvidarse que la soberanía es una categoría histórica y que, como tal, debe entendérsela conforme a las circunstancias que provocaron su nacimiento. El Estado moderno debía afirmarse como poder absoluto, y eso significaba que debía liberarse del poder de la Iglesia y del Imperio Romano, y someter bajo su autoridad a los señores feudales y las corporaciones. Entendido en su momento histórico, el poder absoluto del Estado es un poder relativo. Desconoce la autoridad de cualquier poder político distinto al suyo, pero no niega su existencia. Los reclamos son por la independencia, y es eso lo que quiere decir "poder absoluto libre de toda ley sobre ciudadanos y súbditos" (Bodin). Es por eso que la solución clásica al problema de la soberanía tiene el mérito de ser una solución histórica. Presenta la soberanía con el sentido que quiso imprimirle al erigirla en concepto político. La presenta tal y cual fue su origen en el siglo XVI: la absoluta independencia del Estado respecto de los poderes extranjeros - Iglesia e Imperio Romano- y su absoluta superioridad respecto de sus súbditos — - señores feudales y corporaciones. La soberanía es, por tanto, un concepto negativo, pues no expresa lo que es, sino lo que no es: no es dependencia ni es sumisión”. Para todo, véase: Andaluz, Horacio, Positivismo normativo y Derecho Internacional (1 $1^{\text {a }}$ edición, La Paz, Plural, 2005), pp. 52-54. 
al margen de la unidad jurídica, concibieron para la costumbre un papel enteramente secundario, asignando la primacía al Derecho de fuente estatal ${ }^{35}$. Así se explica que la costumbre haya perdido protagonismo como fuente de producción normativa, y así se llega a que en el Derecho nacional las relaciones entre fuentes se resuelvan por la primacía del Derecho de fuente estatal, importando la costumbre sólo en tanto el Derecho del Estado la confirme o remita a ella (costumbre secundum legem) ${ }^{36}$ o en tanto regule cuestiones no contempladas en la ley (costumbre praeter legem), en cuyo caso su existencia se funda en su propia eficacia y su aplicación subsidiaria haya justificación en la integridad del sistema jurídico.

En el caso del Derecho indígena originario campesino, se trata de una costumbre secundum legem: existe como fuente productora de Derecho en los distintos subsistemas normativos autónomos indígena originario campesinos en la medida que la Constitución remite a él (artículos 30.II.14, 190.I y 191.I), por lo que es válido siempre que no sea contrario a los derechos y garantías constitucionales (artículo 190.II) y se desarrolle dentro de las competencias atribuidas por la Constitución a estos subsistemas (artículo 304). Es, por tanto, una fuente subordinada a la Constitución y

${ }^{35}$ Para los teóricos absolutistas, la costumbre "sólo tiene fuerza por tolerancia y en tanto que place al príncipe soberano, quien puede convertirla en ley mediante su homologación. En consecuencia, toda la fuerza de las leyes civiles y costumbres reside en el poder del príncipe soberano". "La ley puede anular las costumbres, pero la costumbre no puede derogar la ley": Bodin, Jean, Los seis libros de la república (1a edición, Madrid, Centro de Estudios Constitucionales, 1992), pp. 46, 66 y 67. En el mismo sentido: "cuando el uso prolongado obtiene la autoridad de una ley, no es la extensión del tiempo lo que determina su autoridad, sino la voluntad del soberano expresada mediante su silencio": HobBEs, Thomas, Leviathan (1 $1^{a}$ edición, Nueva York, Penguin, 1968), p. 348. El triunfo de las revoluciones liberales no cambió la visión respecto de la costumbre: las tesis liberales coinciden con las absolutistas en la defensa del monopolio legal de la producción jurídica, porque, por un lado, la ilustración ve en la costumbre los prejuicios e ignorancia de los siglos anteriores que deben ser barridos por la razón, cuya expresión es la ley, y, por otro lado, la ley permite certeza y regulación uniforme, versus la inseguridad sobre el conocimiento del Derecho vigente que acarrea la costumbre y la desigualdad en las relaciones jurídicas que produce, fruto de ser una técnica de regulación descentralizada aplicada en sociedades fragmentadas (estamentos, gremios).

${ }^{36} \mathrm{~A}$ manera de ejemplo, los casos en los que el Derecho de fuente estatal confirma o reenvía a la costumbre son aquellos en los que expresamente se establece la vigencia de la costumbre en una cierta relación jurídica. Estos casos se identifican por el uso de expresiones como las siguientes: "cuando los usos lo autorizan" (artículo $460 \mathrm{del}$ Código Civil), "según los usos" (artículo 520 del Código Civil), o "sujetándose a los usos" (artículo 1142 del Código Civil). También puede ocurrir que el Derecho legislado utilice expresiones que remiten a prácticas sociales, tales como "comportarse como un buen padre de familia”. 
cuya existencia es válida en los términos normados por ella. En este sentido, la Constitución se ha apegado a la naturaleza jurídica de la costumbre, reglando en consecuencia. Por ello que disponga que el Derecho indígena originario campesino sea de base personal (artículo 191.II.1), pues al ser la costumbre una técnica de producción normativa descentralizada, su ámbito de aplicación no puede ser más que personal, desde que la práctica consuetudinaria no obliga a quienes no han participado en su formación. Así, lo que la Constitución llama vigencia territorial debe tomarse como ámbito espacial de aplicación de la costumbre a los miembros de una nación o un pueblo indígena originario campesino (base personal), y ese espacio es el respectivo territorio autonómico, en que sus autoridades tradicionales están habilitadas por la Constitución para ejercer funciones jurisdiccionales, conforme se desprende del artículo 191.II.3 "esta jurisdicción se aplica" "dentro de la jurisdicción de un pueblo indígena originario campesino").

En lo que respecta a las relaciones del Derecho indígena originario campesino con las normas de fuente formal, éstas son: i) de subordinación a la Constitución, a los respectivos estatutos de autonomías indígenas y a la Ley de Deslinde Jurisdiccional, pues la costumbre existe por la remisión de la Constitución en los términos que deberá legislar la Ley de Deslinde Jurisdiccional (artículo 191.II.2) ${ }^{37}$, a saber, en consecuencia con la cosmovisión indígena originaria campesina (artículo 30.II.14), en cuanto no implique irrespeto a los derechos y garantías constitucionales (artículo 190. II) ni rebasar las materias atribuidas a los subsistemas indígena originario campesinos, lo que, a su vez, conlleva la subordinación a sus respectivos estatutos autónomos (artículo 304); y ii) con relación a las fuentes formales de los otros subsistemas normativos, no se aplican los criterios de jerarquía, temporalidad ni especialidad, por cuanto la costumbre pertenece a un subsistema normativo autónomo, por lo que su relación con las demás fuentes pasa por la competencia constitucional de este subsistema, haciendo que la costumbre rija respecto de los miembros de los pueblos indígena

${ }^{37}$ El texto de la Constitución remite a la Ley de Deslinde Jurisdiccional la determinación del ámbito material de regulación consuetudinaria (artículo 191.II.2). Su propio nombre indica que el objeto de la Ley de Deslinde Jurisdiccional es delimitar el ámbito propio de la jurisdicción indígena originaria campesina en sus relaciones con las jurisdicciones ordinaria, agroambiental y constitucional, y eso pasa por definir las materias objeto de regulación consuetudinaria, en cuya aplicación se ejercerá la jurisdicción. En esta tarea la Ley de Deslinde Jurisdiccional no procede ad libitum, sino en el marco de las competencias atribuibles a los subsistemas indígena originario campesinos (artículo 304), no hacerlo así supondría violar la distribución constitucional de competencias. 
originaria campesinos en sus respectivos territorios y dentro del ámbito material de aplicación de sus respectivos estatutos autonómicos.

Lo dicho significa: i) que las decisiones de la jurisdicción indígena originario campesina son recurribles en la jurisdicción constitucional, en la medida que sean violatorias de los derechos garantizados por la Constitución, porque éstos son el límite a la obligación de "toda autoridad pública o persona [de acatar] las decisiones de la jurisdicción indígena originaria campesina" (artículo 192.I); ii) que el ejercicio de la jurisdicción indígena originario campesina puede ser contestado por las jurisdicciones ordinaria y agroambiental, en cuyo caso es el Tribunal Constitucional Plurinacional el que decide el asunto (artículo 202.11); y iii) que si lo que está en controversia es la efectiva existencia de una determinada práctica consuetudinaria (precondición para el ejercicio de la jurisdicción), la misma deberá probarse ${ }^{38}$, pues, por su propia naturaleza, la regla iura novit curia no corre respecto a la costumbre.

4. Los decretos, reglamentos y demás resoluciones emanadas de los órganos ejecutivos correspondientes.

El artículo 410.II.4 de la Constitución se refiere a la vez a las normas (decretos, resoluciones) producidas por los órganos ejecutivos (centrales y descentralizados o autónomos), y al ejercicio de la potestad reglamentaria (reglamentos) que les corresponde. Este artículo debe leerse según la competencia material de los distintos órganos productores, por ser el criterio utilizado por la Constitución para estructurar las fuentes a este nivel. Así, las relaciones entre normas de fuente central y de fuente descentralizada y autónoma no se rigen por los criterios de jerarquía, temporalidad ni especialidad (inaplicables entre normas de distintos subsistemas), sino por el criterio de competencia. Esto implica la invalidez del acto normativo producido por un órgano fuera de su marco competencial.

En relación al órgano ejecutivo central, desde 1826 el texto de la Cons-

\footnotetext{
${ }^{38} \mathrm{Al}$ estar formada por hechos, las reglas consuetudinarias son objeto de prueba, pues de otro modo no puede verificarse su existencia más allá del alegato de la parte que la invoca. Así es en el Derecho internacional, en que la carencia de órganos productores centralizados hace que la costumbre tenga el protagonismo que otrora lo tuvo en el Derecho interno: "[en] las reglas consuetudinarias la existencia de la opinio iuris de los Estados se prueba por vía de inducción, tomando como punto de partida el análisis de una práctica suficientemente amplia y convincente, y no por vía de deducción a partir de ideas concebidas a priori" (Delimitación de la frontera marítima en la región del Golfo de Maine, Canada/Estados Unidos, ICJ Reports-CIJ Recueil, 1984, p. 284). También los derechos estatales exigen la prueba de la costumbre. Dice el Código Civil de España: "La costumbre sólo regirá en defecto de ley aplicable, siempre que no sea contraria a la moral o al orden público y que resulte probada" (artículo 1.3).
} 
titución amarró la potestad reglamentaria a la potestad ejecutiva, lo que hizo que desde su redacción la competencia formal del órgano ejecutivo para producir Derecho se presentase siempre expresamente circunscrita a las leyes ${ }^{39}$. Hoy la Constitución ha roto con esa redacción, presentando tal competencia en un texto separado, que dice que el órgano ejecutivo produce Derecho en la forma de decretos supremos y resoluciones (artículo 172.8). El hecho es que aunque la redacción ha cambiado, la norma no lo ha hecho: la competencia formal del órgano ejecutivo para producir Derecho requiere de habilitación legislativa previa para su ejercicio (regla general), salvo cuando la ejerza en cumplimiento de competencias directamente atribuidas por la Constitución.

Para comenzar por la excepción, en un Estado de Derecho la actuación de los poderes públicos es lícita cuando va precedida de una norma habilitante de competencia. Así, el sometimiento a la Constitución significa que los poderes públicos actúan sólo en virtud de competencias expresas o de poderes implícitos. Poderes implícitos son los ejercidos como medios constitucionalmente lícitos para el cumplimiento de competencias expresas. Tanto competencias expresas como poderes implícitos están limitados por la reserva de competencias a favor de otros órganos del poder público y por la prohibición de alterar los principios, derechos y garantías constitucionales ${ }^{40}$. Llevado esto a la competencia normativa del órgano ejecutivo,

${ }^{39}$ Decía el texto de 1826: "es atribución del Presidente de la República autorizar los reglamentos y órdenes para el mejor cumplimiento de la Constitución, las leyes y los tratados públicos" (artículo 83.5). El texto vigente hasta 2009 decía: "es atribución del Presidente de la República ejecutar y hacer cumplir las leyes, expidiendo los decretos y órdenes convenientes, sin definir privativamente derechos, alterar los definidos por Ley ni contrarias sus disposiciones, guardando las restricciones consignadas en esta Constitución" (artículo 96.1). Con el lenguaje propio de la dogmática de la época, el texto de 1861 definía muy bien el objeto de la capacidad normativa del Poder Ejecutivo: "es su atribución] expedir las instrucciones y reglamentos que sean necesarios para la ejecución de las leyes, cuidando de no alterar su espíritu con excepciones reglamentarias" (artículo 54.2).

${ }^{40}$ Limitarse a afirmar que el principio de legalidad se satisface con la actuación conforme al Derecho por parte de los órganos públicos es redundante y peligroso para la libertad democrática: redundante porque la prohibición de actuación contraria a normas es consecuencia de la propia existencia de éstas, por lo que la prohibición de actuación antijurídica es esencial a la existencia de un sistema de Derecho; y peligroso para la libertad democrática porque puede prestarse a una lectura abusiva de la cláusula general excluyente (todo lo que no está jurídicamente prohibido está jurídicamente permitido, artículo 14.IV de la Constitución), que extienda impropiamente su ámbito de validez personal a los poderes públicos, pasando por alto, primero, que la cláusula está inserta en el título correspondiente a las garantías de la persona, lo que siembra la presunción a favor de su aplicabilidad a la persona y no a 
resulta que la Constitución no ha alterado la herencia republicana en la materia, pues innovar en este campo habría supuesto distribuir las materias a legislarse entre el órgano ejecutivo y el órgano legislativo, lo que ciertamente no ha ocurrido. De manera que en el orden constitucional vigente la ley sigue gozando de una reserva formal que, por su posición jerárquica a correlato con la naturaleza y la finalidad del órgano que la genera y la legitimidad que su conformación traduce, hace que sólo la ley pueda regular todo lo que la Constitución no ha atribuido a otros órganos ${ }^{41}$. De ahí que

los poderes públicos y, segundo, que aun cuando no estuviese inserta en dicho título, el resultado sería el mismo (aplicable a la persona y no a los poderes públicos), por cuanto lo contrario supondría hacer de la Constitución una norma superflua, ya que el objeto de la Constitución no es dejar en la orfandad al ciudadano administrado ante los poderes públicos de los que él mismo es fuente, sino instituir un gobierno limitado por el Derecho, lo cual sería una meta de suyo imposible si al Estado le estaría permitido todo lo que no está prohibido. Por eso el énfasis en las competencias expresas: "la autoridad administrativa no solamente debe abstenerse de actuar contra legem, sino que además está obligada a actuar solamente secundum legem, o sea en virtud de habilitaciones legales": CARré De MalberG, R., Teoría general del Estado (reimpresión, México D.F., Fondo de Cultura Económica, 2000), p. 449. Respecto a los poderes implícitos, un buen antecedente de Derecho comparado es la sentencia de Marshall en "McCulloch c. Maryland" (1819): "déjese que el fin sea legítimo, que esté dentro del ámbito de la Constitución, y todos los medios que le sean apropiados, que se adecuen plenamente a ese fin y que no estén prohibidos, sino que coincidan con la letra y espíritu de la Constitución, son constitucionales" (17 U.S., 4 Wheat, 316). En el Derecho internacional la doctrina de los poderes implícitos también ha sido reconocida judicialmente en el asunto "Reparación por daños sufridos al servicio de las Naciones Unidas" (ICJ Reports-CIJ Recueil, 1949), al declararse el Derecho de las Naciones Unidas a reclamar la reparación por la muerte de su mediador en la guerra árabe israelí de 1948, Bernadotte. En el Derecho boliviano el antiguo Tribunal Constitucional dijo que la competencia era conferida expresa o en "forma razonablemente implícita" por la Constitución y las leyes (STC 054/01-RDN, 16 de julio), donde lo reprochable es que no definir lo "razonablemente implícito" puede leerse como invitación al abuso de las competencias expresas, por ello que en el texto principal se haya querido recordar que si hay poderes implícitos los mismos i) se conciben como medios constitucionalmente válidos (lícitos) para el cumplimiento de competencias expresas; y ii) están limitados por la reserva material de competencias a favor de otros órganos del poder público y por la prohibición de alterar los principios, derechos y garantías constitucionales.

${ }^{41}$ La idea de reserva formal ("la ley lo puede todo", dentro del límite dicho) pareciera hacer irrelevante el principio de reserva legal, que supone que una materia sólo pueda ser regulada por ley formal, que es el caso, por ejemplo, de los derechos y garantías constitucionales (artículo 109.II) y de los impuestos nacionales (artículo 158.23). Pero eso no es cierto, por cuanto en la organización estatal de legitimidad democrática el objeto del principio de reserva legal consiste en imponer al legislador el deber de regular por sí mismo una materia determinada, lo que conlleva limitar su 
el órgano ejecutivo no tenga poderes legislativos generales, y que por atribución directa de la Constitución su competencia para producir Derecho le venga constitucionalmente limitada a determinados actos administrativos individualizados (designaciones y nombramientos, etc.) o al dictado de ciertas normas generales cuya materia está fuertemente regulada por la Constitución, como el estado de excepción (artículo 172.26).

Pasando ahora a la regla general, la necesidad de habilitación legislativa previa para el ejercicio de la capacidad normativa del órgano ejecutivo, se explica por la posición que sus normas ocupan en la estructura del sistema, y que está determinada por su relación con las leyes. La superioridad de las leyes sobre las normas del órgano ejecutivo se funda: i) en la mayor complejidad de su proceso de producción, lo que dota a las leyes de fuerza jurídica superior a los decretos y las resoluciones del órgano ejecutivo (razón de teoría jurídica); y ii) en la mayor legitimidad democrática de su órgano productor (razón de teoría política). Pues bien, si a la superioridad de la ley se suma que el órgano ejecutivo carece de poderes legislativos generales, lo evidente es que como regla tal órgano no puede ejercer más que la competencia normativa que previamente le haya sido habilitada por ley. La habilitación es expresa cuando las leyes disponen que deba reglamentarlas, e implícita cuando, no habiendo tal mandato reglamentario expreso, el ejecutivo necesite reglamentarlas para su mejor cumplimiento (artículo 172.1). En este último caso, la reglamentación es el medio constitucionalmente válido (poder implícito) para el ejercicio de la potestad ejecutiva (competencia expresa). Fuera de los casos dichos, adelantarse a la ley supondría que el órgano ejecutivo se atribuyese los poderes legislativos generales de los que carece ${ }^{42}$.

En cuanto a los órganos ejecutivos de las entidades territoriales descentralizadas y autónomas, es aplicable, mutatis mutandis, lo dicho para el

capacidad para dejar a la potestad reglamentaria la regulación de la materia objeto de reserva ("potestas delegata non potest delegari”: porque la delegación violaría la norma de competencia que estableció la reserva). En cambio, en la organización estatal de legitimidad monárquica, que es donde apareció la formulación original del principio, la reserva de ley suponía limitar la capacidad normativa general del órgano ejecutivo, excluyendo de su competencia determinadas materias, pues como se asumía que el poder del monarca era un Derecho propio por su carácter originario (anterior a la Constitución), entonces a él le correspondían todas las competencias que la Constitución no le había privado (una norma general excluyente a su favor), de ahí que surgiese la técnica de las reservas, como medio para evitar que la regulación de determinados asuntos de directo interés para los súbditos quedase a las anchas del monarca, tales como la propiedad y la libertad.

${ }^{42}$ En el sentido argumentado, la lacónica redacción del artículo 172.8 es técnicamente suficiente. 
órgano central. Esto supone la inferioridad jurídica de sus normas respecto a las producidas por sus respectivos órganos legislativos, los mismos que carecen de competencia legislativa general, salvo que la norma suprema de los subsistemas descentralizados y autónomos disponga lo contrario.

Por último, cuando el artículo 410.II.4 se refiere a las "demás resoluciones emanadas de los órganos ejecutivos correspondientes", se está refiriendo al resto de normas producidas por estos órganos, cuya regulación la hace el Derecho ordinario. A nivel del órgano ejecutivo central, tradicionalmente las "demás resoluciones" se han estructurado en forma jerárquica, atribuyendo mayor fuerza jurídica a las formas de más difícil producción; así prima, por ejemplo, la resolución biministerial sobre la ministerial (artículo 8.I de la Ley $\mathrm{N}^{\circ} 3351$ de 21 de febrero de 2006). Desde luego, en sus relaciones mutuas las resoluciones emanadas de los órganos ejecutivos descentralizados y autónomos, y las emanadas del órgano central, se rigen por la competencia material de sus respectivos órganos productores.

\section{CONCLUSIÓN: LA ESTRUCTURA DEL SISTEMA JURÍDICO BOLIVIANO}

Dadas las relaciones entre sus fuentes, son los criterios de jerarquía y de competencia los que determinan la estructura del sistema jurídico boliviano (sistema nacional). Según el criterio de competencia, a partir de su tercer nivel jerárquico el sistema está organizado en subsistemas normativos. Uno de ellos es el subsistema central; los demás los distintos subsistemas descentralizados y autónomos, incluyendo los subsistemas indígena originario campesinos. Dichos subsistemas están en pie de igualdad; sus normas no se derogan recíprocamente, desde que se estructuran según la competencia material de sus distintos órganos productores. Así, la estructura del sistema es la siguiente:

a) En el sistema nacional la supremacía jerárquica corresponde a la Constitución, según resulte interpretada por el Tribunal Constitucional Plurinacional (carácter vinculante de los precedentes constitucionales). Por Constitución se entiende: su texto formal, los tratados sobre derechos humanos ratificados por el país y las normas de Derecho comunitario (también ratificadas si su naturaleza es convencional o incorporadas según lo establezcan las normas originarias tratándose de Derecho comunitario derivado).

b) Siguiendo con el sistema nacional, subordinadas directamente a la Constitución están: i) las leyes aprobadas por dos tercios (las leyes expresas que levanten la prohibición de asentamiento de extranjeros en la zona de seguridad fronteriza y la Ley Marco de Autonomías y Descentralización); y ii) los tratados sobre cuestiones limítrofes y aquellos de cualquier materia 
(menos los que corresponden al bloque de constitucionalidad) que eventualmente hayan sido aprobados por referendo popular, si es que se toma la primera interpretación propuesta (rango supralegal para los tratados aprobados por referendo popular vinculante).

c) En un tercer nivel nacional, también subordinadas directamente a la Constitución por razón de la competencia material de sus respectivos órganos productores, estarían: i) las leyes ordinarias, subordinadas además a las leyes aprobadas por dos tercios; ii) los estatutos autonómicos y las cartas orgánicas, subordinados también a la Ley Marco pero no a las leyes expresas; y iii) los tratados, si es que se toma la segunda interpretación propuesta (rango de ley pero mayor fuerza jurídica pasiva).

d) A partir del tercer nivel nacional, la estructura del sistema se define sólo en términos de competencia. Comenzando con los subsistemas normativos descentralizados y autónomos, su estructura es la siguiente: i) la supremacía en cada subsistema la ostentan los respectivos estatutos autonómicos y cartas orgánicas, que pertenecen al tercer nivel del sistema nacional; ii) subordinadas a los estatutos o cartas, según corresponda, están las normas de los órganos legislativos de cada subsistema; y iii) subordinadas a las normas de sus órganos legislativos están las de normas de sus respectivos órganos ejecutivos, salvo cuando éstos ejerzan competencias normativas derivadas directamente de la norma suprema de sus subsistemas. También son subsistemas normativos autónomos los subsistemas indígena originario campesinos, en los cuales se aplica su Derecho consuetudinario en las materias reconocidas en sus respectivos estatutos indígenas, en ejecución de la distribución de competencias entre los distintos subsistemas normativos efectuada por la Constitución.

(5) Por último, también subordinadas al tercer nivel del sistema nacional, en el subsistema central siguen las normas del órgano ejecutivo (decretos y resoluciones supremas), que tienen a las leyes como fuente de validez, salvo que se trate del ejercicio de atribuciones constitucionales directas; y de ahí, en los subsiguientes niveles, siguen las demás normas producidas por las distintas reparticiones del órgano ejecutivo central, según la ordenación jerárquica establecida por sus normas de fuente legal.

[Recibido el 13 de mayo y aprobado el 21 de septiembre de 2009].

\section{BIBLIOGRAFÍA}

Andaluz, Horacio, El Derecho internacional en el sistema de fuentes: propuesta de artículos para la nueva Constitución de Bolivia, en Revista Boliviana de Derecho 6 (2008) [reproducido en Anuario Mexicano de Derecho Internacional 8 (2008) y en Anuario de Derecho Constitucional Latinoamericano 15 (2009)]. 
Andaluz, Horacio, La justicia constitucional en el Estado de Derecho, en Revista General de Derecho Público Comparado 4 (2009).

Andaluz, Horacio, Positivismo normativo y Derecho internacional (1 a edición, La Paz, Plural, 2005).

Asbun, Jorge, Estudios constitucionales (1a edición, Santa Cruz, El País, 2008).

Bodin, Jean, Los seis libros de la república (1 ${ }^{\text {a }}$ edición, Madrid, Centro de Estudios Constitucionales, 1992).

Carré de Malberg, R., Teoría general del Estado (reimpresión, México D.F., Fondo de Cultura Económica, 2000).

Código Civil de Bolivia.

Código Civil de España.

Constitución de Bolivia (2009).

Goodhart, Arthur L., Determining the Ratio Decidendi of a Case, en Yale Law Journal 40 (1930).

Hart, H. L. A., The Concept of Law (2a edición, Nueva York, Oxford University Press, 1994).

Hobbes, Thomas, Leviathan (1a edición, Nueva York, Penguin, 1968).

Kelsen, Hans, Introduction to the Problems of Legal Theory (1 $1^{\text {a }}$ reimpresión, Nueva York, Clarendon Press, 2002).

KeLsen, Hans, Teoría general del Derecho y del Estado (5a reimpresión, México D.F., UNAM, 1995).

KuCSKO-Stadlmayer, Gabriele, La contribución de AdolfMerkl a la teoría pura del Derecho, en Revista de la Facultad de Derecho de México 244 (2005), pp. 243-258.

Digesto de Justiniano

Ley de Deslinde Jurisdiccional de Bolivia.

Ley Orgánica de Municipalidades de Bolivia (Ley Nº 696 de 10 de enero de 1985).

Ley Orgánica del Ministerio Público de Bolivia (Ley No 2175 de 13 de febrero de 2001).

Llewellyn, Karl, The Bramble Bush (reimpresión, Nueva York, Oceana/Oxford University Press, 1961).

MAYER, Heinz, La teoría de la construcción jurídica escalonada, en WaLTer, Robert; Problemas centrales de la teoría pura del Derecho ( $1^{\text {a }}$ edición, Bogotá, Universidad Externado de Colombia, 2001).

MERRYMAN, John Henry, La tradición jurídica romano-canónica (8a reimpresión, México D.F., Fondo de Cultura Económica, 2003).

Raz, Joseph, Practical Reason and Norms (reimpresión, Nueva York, Oxford University Press, 2002).

Raz, Joseph; The Concept of a Legal System (2a edición, Nueva York, Oxford University Press, 1980).

Rivera Santibáñez, José Antonio, El Tribunal Constitucional en el nuevo modelo de Estado, en Justicia constitucional y Estado de Derecho 10 (2006).

SCHWABE, Jurgen, Cincuenta años de jurisprudencia del Tribunal Constitucional Federal alemán ( $1^{\text {a }}$ edición, Montevideo, Fundación Konrad Adenauer, 2003). 